\title{
FiRST IDENTIFICATION OF SUDOITE IN CaribBean Ceramic-Age Lapidary CraftSManship
}

Alain Queffelec, Ludovic Bellot-Gurlet, Eddy Foy, Yannick Lefrais, and Emmanuel Fritsch

Lapidary craftsmanship was an important part of the material culture of Amerindians in the Antilles during the Early Ceramic period (400 BCE to $400 \mathrm{CE}$ ). Exhaustive analysis of archaeological beads and pendants from the French islands of the Lesser Antilles has revealed a green lapidary material used for the production of nine artifacts from five archaeological sites: sudoite. This di-trioctahedral member of the chlorite group has the relatively simple chemical formula of $\mathrm{Mg}_{2} \mathrm{Al}_{3} \mathrm{Si}_{3} \mathrm{AlO}_{10}(\mathrm{OH})_{8}$. Previously unknown in sizes suitable for carving, it has never before been identified in any lapidary production and therefore warranted a multi-analytical nondestructive approach to confirm this identification. The analysis was conducted through Raman spectroscopy, FTIR spectroscopy, and X-ray diffraction. The texture and the chemical composition were assessed through SEM-EDS. Color, UV luminescence, and other gemological parameters were studied through standard gemological methods, UV-Vis-NIR spectroscopy, and fluorimetry. Finally, the provenance of the material is considered following a geological approach. The recovery of sudoite artifacts in several archaeological Amerindian sites of the Lesser Antilles supports the already established theory of a pan-Caribbean trade network as old as the first several centuries Before the Common Era.

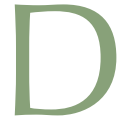
uring the Early Ceramic age, between 400 BCE and 400 CE (Bérard, 2019), a people from northeastern South America appropriated the entire Lesser Antilles, replacing or assimilating the inhabitants of these Caribbean islands (Hofman et al., 2007; Wilson, 2007; Nägele et al., 2020). Indeed, these fishermen-cultivators arrived on the islands with a great innovation: ceramic technology. Several cultural components existed within this period, with a common background called Saladoid, named after the site of Saladero (Rouse, 1992; Bérard, 2019). The inhabitants of the West Indies at this time possessed a complex culture, some characteristics of which are common to the different islands and sub-periods. These include certain ceramic decorations, simple lithic tools, the important use of shells for tools and adornment, and distinctive funerary practices (Bérard, 2013). The lapidary craft, which will be of particular interest to us in this work, is very diversified in terms of both forms and raw materials (Cody, 1993; Murphy

See end of article for About the Authors and Acknowledgments.

Gems \& Gemology, Vol. 57, No. 3, pp. 206-226,

http://dx.doi.org/10.5741/GEMS.57.3.206

(C) 2021 Gemological Institute of America et al., 2000; Queffelec et al., 2018; Falci et al., 2020; Queffelec et al., 2020). These materials and artifacts are the subject of various studies examining the supply, distribution, and trade networks of the fishermen-cultivators who inhabited the entire archipelago but whose origins can be traced back to the northeastern part of South America.

\section{In Brief}

- Analysis of beads and pendants from several archaeological sites in the Lesser Antilles has revealed the first documented use of sudoite in lapidary craftsmanship.

- A multi-analytical process was applied to confirm and describe this material in detail through non-invasive means.

- The provenance of this material is hypothesized to come from ophiolite suture zones located in the Greater Antilles or Mesoamerica.

An exhaustive study of the ornamental objects of this period recovered from archaeological sites in the French West Indies has revealed a material not mentioned in the classic list of "green rocks" used for 


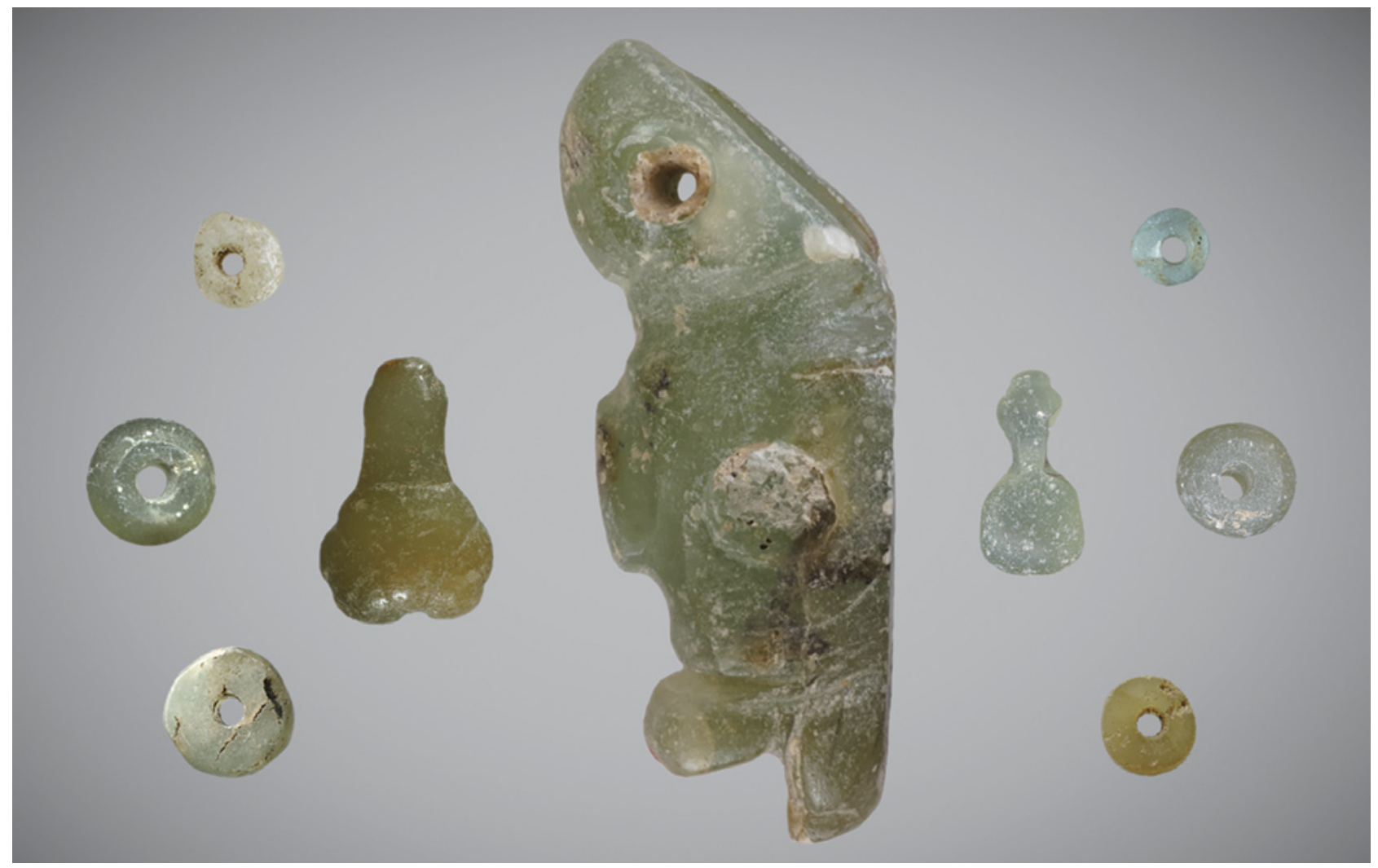

Figure 1. The nine Amerindian archaeological objects identified as sudoite. The beads on the left are, from top to bottom: SM-02-033, GD-02-028, and SM-02-086. The pendants in the center are, from left to right: GD-09-001, GD02-003, and GD-01-017. The beads on the right are, from top to bottom: GD-01-020, GD-01-019, and MA-02-027. The central artifact is $43.5 \mathrm{~mm}$ high. Photos by Alain Queffelec.

the craft: sudoite. This mineral belonging to the chlorite group was named by G. Müller (Müller, 1961; v. Engelhardt et al., 1962) in honor of Toshio Sudo (1911-2000), professor of mineralogy at the University of Tokyo and a pioneer of clay science (Kohyama, 2000). It is a sheet silicate (and thus easy to carve), more precisely a magnesium-rich di-trioctahedral chlorite found mainly in hydrothermal or high-pressure/low-temperature (HP/LT) metamorphism contexts. Its relatively simple chemical makeup, $\mathrm{Mg}_{2} \mathrm{Al}_{3} \mathrm{Si}_{3} \mathrm{AlO}_{10}(\mathrm{OH})_{8}$, does not contain any rare or unusual elements.

Few other chlorite-group minerals have been reported as gems (Bukanov, 2006), and sudoite is not listed in any gemological compilation (e.g., Desautels, 1973; Arem, 1987; Duda and Relj, 1999; ManutchehrDanai, 2005; O'Donoghue, 2006). It is thus necessary to confirm the mineralogical composition of these nine ornamental objects, initially carried out by Raman spectroscopy and for five artifacts by X-ray diffraction, using a multi-analytical approach that entails nondestructive methodologies applicable to archaeological objects. This mineralogical study will be sup- plemented by a geological analysis in order to provide a better understanding of the distribution and potential provenance of this rare lithic material.

\section{MATERIALS}

Archaeological Artifacts. The nine archaeological objects studied in this work were discovered in five archaeological excavations carried out in Guadeloupe, Martinique, and Saint Martin (figure 1 and table 1). A thorough description and the archaeological context surrounding the artifacts can be found in previous publications (Bonnissent, 2008; Queffelec et al., $2018,2020,2021)$. The inventory numbers are taken from the database that records all the lapidary objects from the Lesser Antilles (Queffelec et al., 2021). The inventory codes consist of two letters identifying the island on which the object was found, two digits indicating the archaeological site on this island, and three digits indicating the number of the object in the site. Of these nine artifacts, five were the subject of extensive study in Bordeaux and Paris, while four have only been analyzed on-site using mobile instru- 
TABLE 1. Description of the nine sudoite artifacts examined in this study.

\begin{tabular}{|c|c|c|c|c|c|c|}
\hline Inventory no. & Island & Archaeological site & Weight (g) & Dimension (mm) & Type & Excavator (year) \\
\hline GD-01-017* & Guadeloupe & Gare Maritime & 0.48 & $13.9 \times 7.2 \times 4.2$ & $\begin{array}{l}\text { Zoomorphic } \\
\text { pendant }\end{array}$ & Romon (2006) \\
\hline GD-01-019* & Guadeloupe & Gare Maritime & 0.51 & $7.9 \times 7.9 \times 6.1$ & $\begin{array}{c}\text { Subspherical } \\
\text { bead }\end{array}$ & Romon (2006) \\
\hline GD-01-020* & Guadeloupe & Gare Maritime & 0.06 & $4.2 \times 4.2 \times 2.1$ & Discoid bead & Romon (2006) \\
\hline GD-02-003 & Guadeloupe & Morel & 14.2 & $43.5 \times 18.5 \times 14.5$ & $\begin{array}{l}\text { Zoomorphic } \\
\text { pendant }\end{array}$ & Durand (1987) \\
\hline GD-02-028* & Guadeloupe & Morel & 0.47 & $8.6 \times 8.6 \times 4.7$ & $\begin{array}{l}\text { Bitronconic } \\
\text { bead }\end{array}$ & Delpuech (1995) \\
\hline GD-09-001* & Guadeloupe & $\begin{array}{l}\text { Cathédrale } \\
\text { Basse-Terre }\end{array}$ & 1.78 & $19.7 \times 13.2 \times 6.4$ & $\begin{array}{l}\text { Zoomorphic } \\
\text { pendant }\end{array}$ & Bonnissent (2004) \\
\hline MA-02-027 & Martinique & Vivé & 0.3 & $6.4 \times 6.8 \times 3.3$ & Discoid bead & Giraud (1999) \\
\hline SM-02-033 & Saint Martin & Hope Estate & 0.1 & $5.6 \times 5.2 \times 3.1$ & Discoid bead & Henocq (1994) \\
\hline SM-02-086 & Saint Martin & Hope Estate & 0.3 & $7.2 \times 7.0 \times 3.2$ & Discoid bead & Henocq (1994) \\
\hline
\end{tabular}

*Artifacts studied in detail in Bordeaux and Paris.

ments during two study missions to the Antilles (table 1).

Mineralogy. Sudoite is a phyllosilicate of the chlorite group, with a stacking of sheets (figure 2) formed of T-O'-T layers (T: layer composed of tetrahedra; $\mathrm{O}^{\prime}$ : layer composed of octahedra) separated by O layers (Brigatti et al., 2011). In the T-O'-T layers, the T layers are formed of $(\mathrm{Si}, \mathrm{Al}) \mathrm{O}_{4}$ aluminosilicate tetrahe- dra. They enclose a layer of octahedra whose vertices are $\mathrm{O}^{2-}$ anions or $(\mathrm{OH})^{-}$hydroxyl groups, while the octahedral center is occupied by a cation.

Sudoite, within the chlorite group, is one of the minerals of the di-trioctahedral subgroup (table 2). This implies that the octahedral cationic sites of the T-O'-T sheets are two-thirds (di-) occupied by trivalent cations, here $\mathrm{Al}^{3+}$, creating $\mathrm{O}^{\prime}$ sites of the formula $\mathrm{AlO}_{4}(\mathrm{OH})_{2}$. The octahedral cationic sites of the

Figure 2. Representation of the sudoite mineralogical structure, projected down the b-axis. Modified after the cookeite structure (Wikimedia Commons).

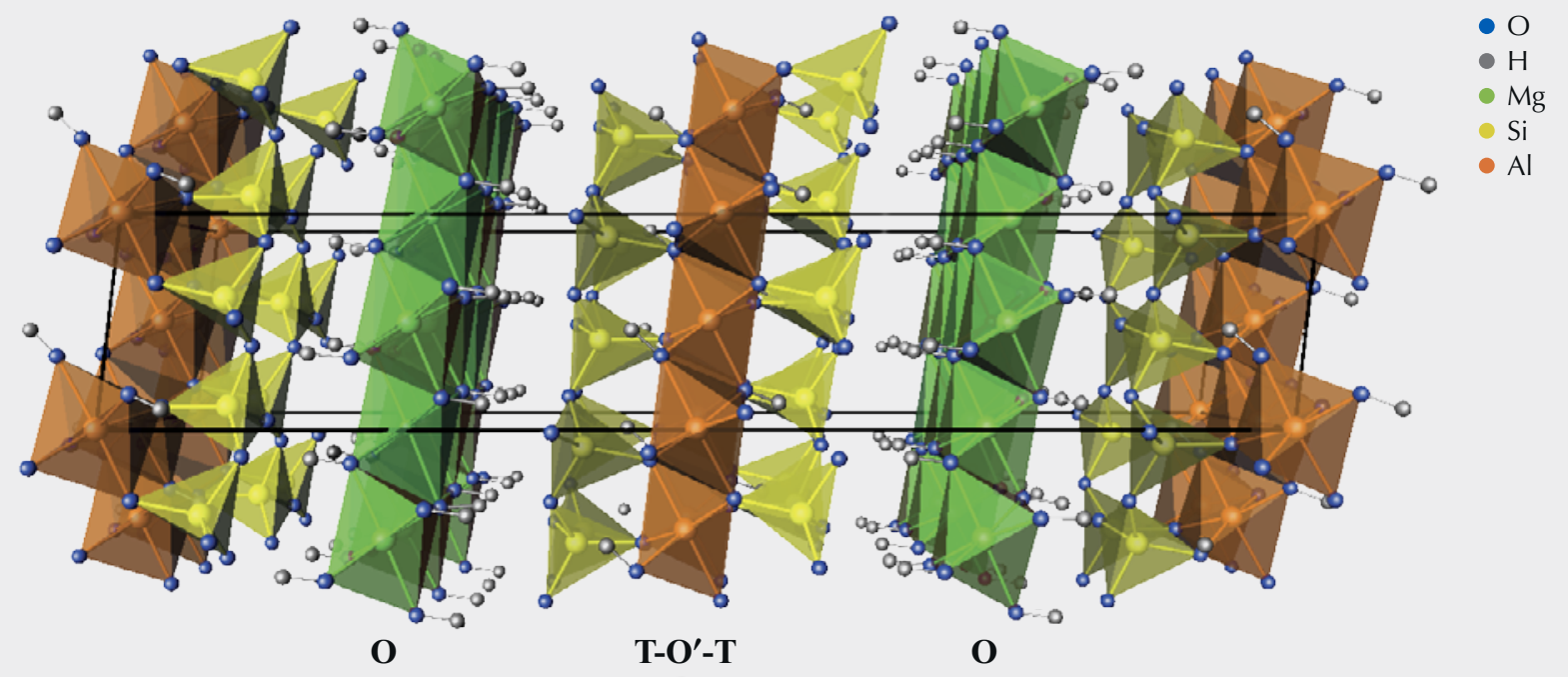


TABLE 2. Classification of the minerals from the chlorite group as a function of octahedral site composition (modified after Bailey, 1980).

\begin{tabular}{lcc}
\hline Layer T-O'-T & Interlayer space $\mathrm{O}$ & Mineral name \\
\hline Dioctahedral & Dioctahedral & Donbassite \\
Dioctahedral & Trioctahedral & Cookeite, sudoite \\
Trioctahedral & Dioctahedral & Unknown \\
Trioctahedral & Trioctahedral & $\begin{array}{c}\text { Brunsvigite, chamosite, } \\
\text { clinochlore, diabantite, } \\
\text { penninite, ripidolite, } \\
\text { sheridanite, thuringite }\end{array}$ \\
\hline
\end{tabular}

O sheets are occupied entirely (tri-) by bivalent cations $\mathrm{Mg}^{2+}$, creating $\mathrm{O}$ sites of the formula $\mathrm{Mg}_{3}(\mathrm{OH})_{6}$.

This structure and the cationic composition of the octahedral sites lead to a sudoite formula of $\mathrm{Mg}_{2} \mathrm{Al}_{3} \mathrm{Si}_{3} \mathrm{AlO}_{10}(\mathrm{OH})_{8}$. This ideal formula is somewhat different from the formulas derived experimentally, which always contain a variable but not negligible proportion of iron in substitution for aluminum at $\mathrm{O}^{\prime}$ sites (e.g., Billault et al., 2002; Ruiz Cruz and de Galdeano, 2005).

\section{METHODS}

With the dual objective of confirming the characterization as sudoite and presenting a first series of gemological parameters for this material, several methods of gemological and mineralogical characterization were deployed on five archaeological objects (table 1), which were temporarily removed to Bordeaux, France. As for the objects that remained in their Caribbean curation site, mineralogical identification relied on portable Raman spectroscopy and basic observation.

The objects were observed with the unaided eye, using a 10× triplet loupe and a Leica Z16APO macroscope, and photographed. Their dimensions were measured with an electronic caliper, and their mass and density were recorded using a hydrostatic balance (Mettler-Toledo XS104) or a conventional balance (Kern TAB 20-3) for objects that remained in the Caribbean. Whenever possible, the refractive index of the objects taken to France was measured using a spot reading method, despite the inherent difficulty of doing so on poorly polished objects. Ultraviolet (UV) luminescence was observed and photographed under short-wave $(254 \mathrm{~nm})$ and long-wave $(365 \mathrm{~nm})$ UV light (Vilber Lourmat VL-6LC, 6W per tube). We examined the optic character of the more translucent artifacts using a GIA Gem Instruments polariscope.

Various complementary methods were applied to the objects when possible in order to confirm and refine our knowledge of this material. Raman microspectroscopy was the first method applied, being used routinely on all the archaeological objects studied in the project to characterize the lithic materials used by the Amerindians to produce ornamental objects in the Saladoid period. The five objects that could be taken to France were analyzed by a Bruker Senterra Raman microspectrometer equipped with a $532 \mathrm{~nm}$ laser, and a 1200-line diffraction grating resulting in a resolution of 3 to $5 \mathrm{~cm}^{-1}$. The objects were analyzed repeatedly and at several locations on each sample with a 50× objective and a nominal laser power of 20 $\mathrm{mW}$ in order to confirm the representativeness of the measured signal. Four objects were analyzed at their place of storage in Martinique, Guadeloupe, and Saint Martin during a second phase of the project (table 1) using a portable Raman spectrometer. This Horiba Jobin-Yvon HE532 Raman microspectrometer was equipped with a fixed 920 lines/mm parabolic grating to record the signal in a fixed spectral window from 80 to $3300 \mathrm{~cm}^{-1}$ with a spectral resolution of about 5 $\mathrm{cm}^{-1}$. The analyses were conducted using a long working distance $50 \times$ objective with a $532 \mathrm{~nm}$ laser whose power was modulated to about $10 \mathrm{~mW}$ on the sample.

Infrared spectroscopy was carried out in attenuated total reflection (ATR) mode using a Bruker Alpha spectrometer, measuring absorbance between 400 and $4000 \mathrm{~cm}^{-1}$ with a resolution of $4 \mathrm{~cm}^{-1}$. In all, 48 scans were carried out to obtain a spectrum of sufficient quality, despite the difficulties encountered in positioning the objects and creating sufficient optical contact between the diamond crystal of the ATR and the archaeological artifact without damaging it.

The objects' mineralogical composition was confirmed by X-ray diffraction. The analyses were carried out using a Rigaku RU200BH X-ray generator, with the $\mathrm{K} \alpha$ line of molybdenum $(\lambda=0.709 \AA)$. Measurements were performed either in macrobeam $(100 \mu \mathrm{m})$ in transmission (if the artifact was sufficiently thin) or in microbeam $(30 \mu \mathrm{m})$ in low-angle $\left(5^{\circ}\right)$ reflection configuration (figure 3). The diffraction image was recorded and stored on a photostimulated image detector. After scanning, the image was converted to a $2 \theta$ diagram using Fit2D software (Hammersley, 2016). Using Bruker's Diffrac-EVA software, the diagram was then compared to reference databases from the International Centre for Diffraction Data (ICDD) (Gates-Rector and Blanton, 2019). 


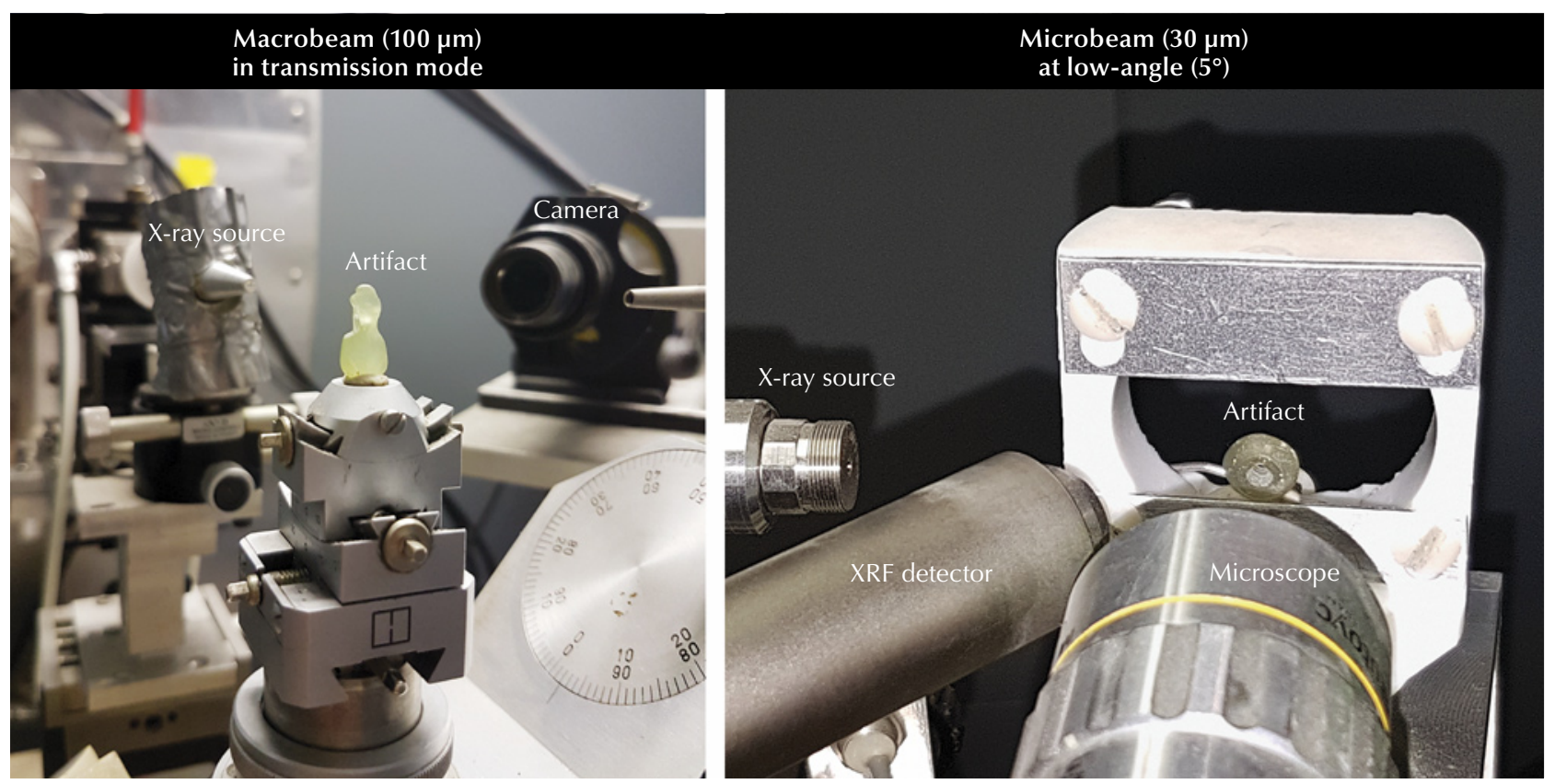

Figure 3. Photographs of macrobeam (left) and microbeam (right) X-ray diffraction setups. The X-ray photostimulated detector is not visible in these images. Photos by Eddy Foy.

A portable energy-dispersive X-ray fluorescence (EDXRF) spectrometer allowed qualitative and semiquantitative characterization. These analyses were carried out using a Bruker Tracer $5 \mathrm{i}$ spectrometer, set at $15 \mathrm{kV}, 100 \mu \mathrm{A}, 300 \mathrm{~s}$, with a 28 micron aluminum filter to remove the L-lines from the rhodium $\mathrm{X}$-ray tube. Since the artifacts did not systematically cover the whole measurement window, and their thickness was variable, the measured signal of all samples was normalized at $11 \mathrm{keV}$. Finally, to ensure that certain lines did not come from the measuring device itself, a Teflon pellet was analyzed with the same device, since this material is supposed to contain only elements that cannot be measured by X-ray fluorescence. This Teflon measurement was carried out without a filter so that the L lines of rhodium could be clearly distinguished.

For quantitative analysis, the objects were analyzed by scanning electron microscope coupled with energy-dispersive $\mathrm{X}$-ray spectroscopy (SEM-EDS) in a JEOL IT500HR microscope (FEG source). The SEM images and EDS spectra were acquired without carbon coating in a low-vacuum mode (here $40 \mathrm{~Pa}$ ). The images were acquired with a backscattered electron detector, while the EDS analysis was performed with two Oxford Ultimax 100 detectors at $20 \mathrm{kV}$ for $30 \mathrm{~s}$, producing spectra with 4.0-4.5 million counts. The chemical quantifications by SEM-EDS in atomic \% were converted into atoms per formula unit, normalized to an anionic composition of $\mathrm{O}_{10}(\mathrm{OH})_{8}$ so that they could easily be compared with the chemical for- mulae known in the literature, both the theoretical formula of the mineral and those measured on natural samples (Bailey and Lister, 1989; Ruiz Cruz and de Galdeano, 2005). The results were also normalized to an anionic composition of $\mathrm{O}_{10}(\mathrm{OH})_{2}$ for comparison with illite. To estimate the volume analyzed, Monte Carlo simulations were conducted in the Casino V2 program (Drouin et al., 2007) using the current $(20 \mathrm{kV})$, matrix composition $(\mathrm{Mg}, \mathrm{Al}, \mathrm{Si}, \mathrm{O})$, and specific gravity (2.65) as parameters.

Two spectrometers were used to obtain the UVVis-NIR absorbance spectra of the archaeological objects: a Magilabs GemmoSphere and a PerkinElmer Lambda 1050 equipped with a 3D accessory and an integrating sphere. Measurements with the first instrument provided limited resolution and spectral range (approximately $1.3 \mathrm{~nm}$ from 365 to $1000 \mathrm{~nm}$ ), while the second instrument allowed a resolution of $1 \mathrm{~nm}$ in the spectral range from 2300 to $300 \mathrm{~nm}$ but required a specific assembly with an accurate placement of the sample upstream of the integrating sphere.

For fluorimetry, we used a Horiba Fluorolog 3. After measuring an emission spectrum with an excitation light set at $420 \mathrm{~nm}$, at a resolution of $1 \mathrm{~nm}$, we obtained an excitation spectrum for the most luminescent object, also at a resolution of $1 \mathrm{~nm}$. In addition, we obtained 3D luminescence spectra, which represent a series of emission spectra (along the $\mathrm{x}$ axis) obtained for a regular sequence of excitation wavelengths (along the y-axis). These 3D spectra 
TABLE 3. Gemological characteristics of the sudoite samples.

\begin{tabular}{|c|c|c|c|c|c|}
\hline Inventory no. & Color & Opacity & Specific gravity & Refractive index & $\begin{array}{l}\text { Long-wave UV luminescence } \\
\text { Intensity and color }\end{array}$ \\
\hline GD-01-017 & Light gray & Translucent & 2.625 & $\sim 1.55$ & Weak green \\
\hline GD-01-019 & $\begin{array}{l}\text { Medium } \\
\text { gray-green }\end{array}$ & Translucent & 2.433 & $1.50-1.60$ & Inert \\
\hline GD-01-020 & $\begin{array}{l}\text { Light gray to } \\
\text { dark green }\end{array}$ & Opaque & 2.244 & - & Weak green \\
\hline GD-02-003 & $\begin{array}{l}\text { Medium dark } \\
\text { grayish green }\end{array}$ & Translucent & - & - & - \\
\hline GD-02-028 & $\begin{array}{l}\text { Light gray to dark } \\
\text { grayish green }\end{array}$ & Translucent & 2.583 & - & Inert \\
\hline GD-09-001 & $\begin{array}{l}\text { Light brown to } \\
\text { medium dark } \\
\text { grayish green }\end{array}$ & Opaque & 2.645 & $\sim 1.55$ & Moderate green-yellow \\
\hline MA-02-027 & $\begin{array}{l}\text { Light to medium } \\
\text { dark grayish brown }\end{array}$ & Translucent & - & - & - \\
\hline SM-02-033 & Very light gray & Translucent & - & - & - \\
\hline SM-02-086 & Light grayish green & Translucent & - & - & - \\
\hline
\end{tabular}

thus illustrate the variation of the emission within the range of possible excitation wavelengths.

\section{RESULTS}

Gemological Properties. Standard gemological observations and measurements were carried out (table 3). Some parameters could be measured only for objects that could be studied outside their place of conservation. The samples here show a certain diversity in terms of opacity and specific gravity. On the other hand, they are all polycrystalline and therefore always appear bright between crossed polarizers; their color is rather homogeneous. Observations revealed a laminated structure, identifiable in some curvatures of the object, where these intersect the main plane of lamination (figure 4). Despite the difficulties in determining the refractive index with a refractometer because of the shape and poor polish of the surface of these archaeological objects, three values between 1.50 and 1.60 were observed, consistent with the values given for chlorite-group minerals, which range between 1.56 and 1.68 (Albee, 1962). Albee (1962) also specifies that a relative decrease in the refractive index is expected when the filling rate of octahedral sites decreases and the magnesium content increases relative to that of iron. In the presence of a di-trioctahedral member of the chlorite group, containing almost only magnesium, it is therefore

Figure 4. This image of the surface of artifact GD-01017 shows the laminar texture of the material. Photomicrograph by Alain Queffelec.

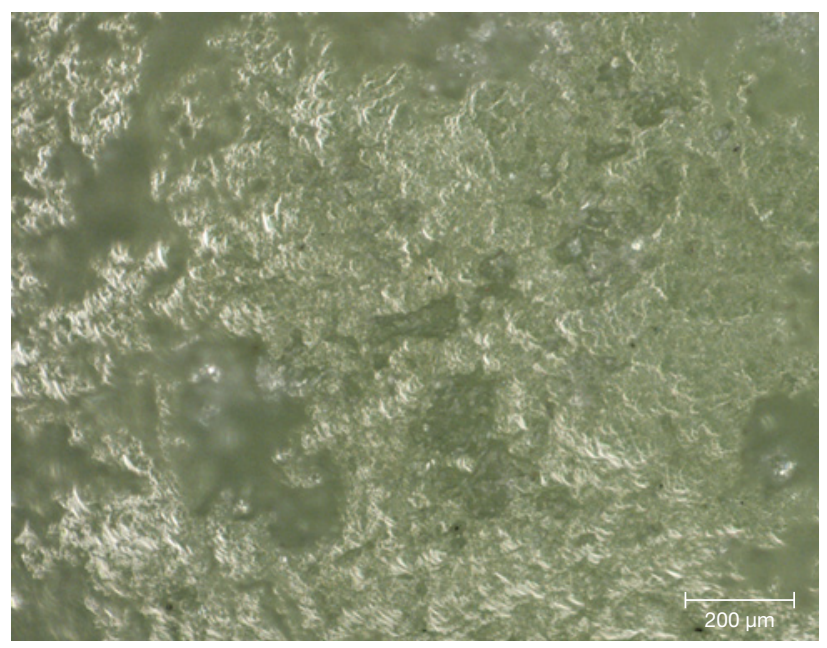



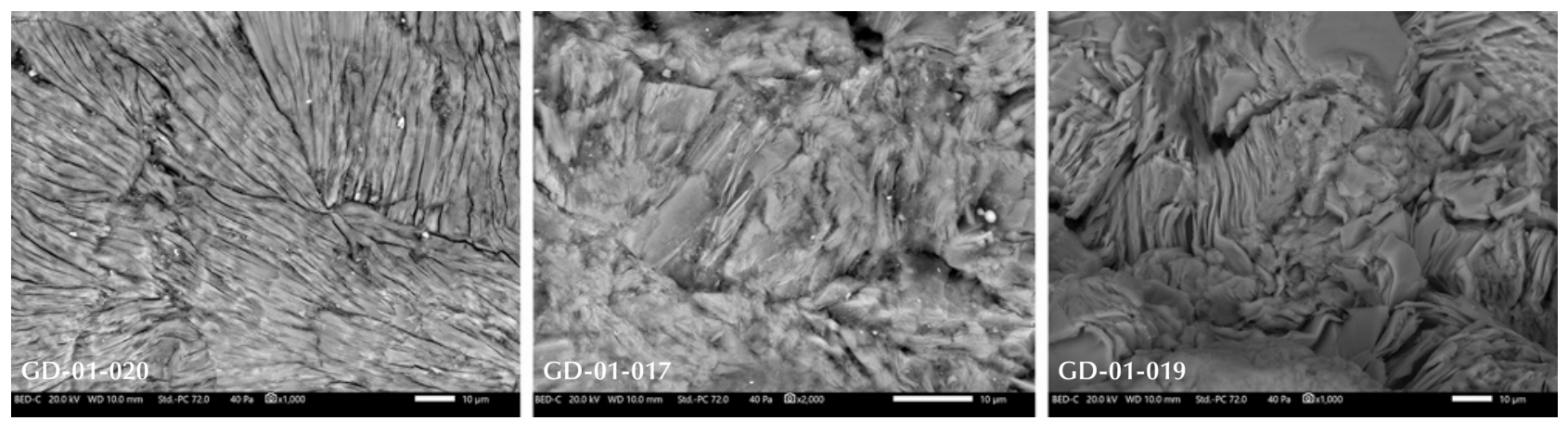

Figure 5. SEM-BSE images of the structure of sudoite, typical for a phyllosilicate (artifacts GD-01-020, GD-01-017, and GD-01-019). Images by Yannick Lefrais.

logical to observe low values in the reported range. No reactions to gemological filters (Chelsea or Hanneman) were noted, and no specific absorption was visible with a handheld spectroscope.

High-Magnification Observation. Backscattered electron (BSE) images acquired by SEM confirm the lamellar structure of the artifacts (figure 5). They also reveal alternating lighter and darker lamellae in some areas of some artifacts (figure 6). This change of grayness level indicates a slight change in chemical composition, with the lighter sheets incorporating heavier elements. Finally, the whole surface of the artifact GD-01-020 shows multidirectional groups of sub-parallel lamellae (figure 5, left) that are not observed in the other samples, where lamellae are poorly organized at a larger scale.

X-Ray Diffraction and Phase Analysis. The diffraction patterns demonstrate the polycrystallinity of the samples and a varying degree of preferential orientation (figure 7). When compared to the PDF2-ICDD crystallographic database, X-ray diffraction clearly confirms the attribution of this material to the chlorite group, and to sudoite in particular (figure 8). The distinction between sudoite and clinochlore is not easy to make by XRD analysis alone, as noted by Bailey and Lister (1989). Three characteristics of the dif-
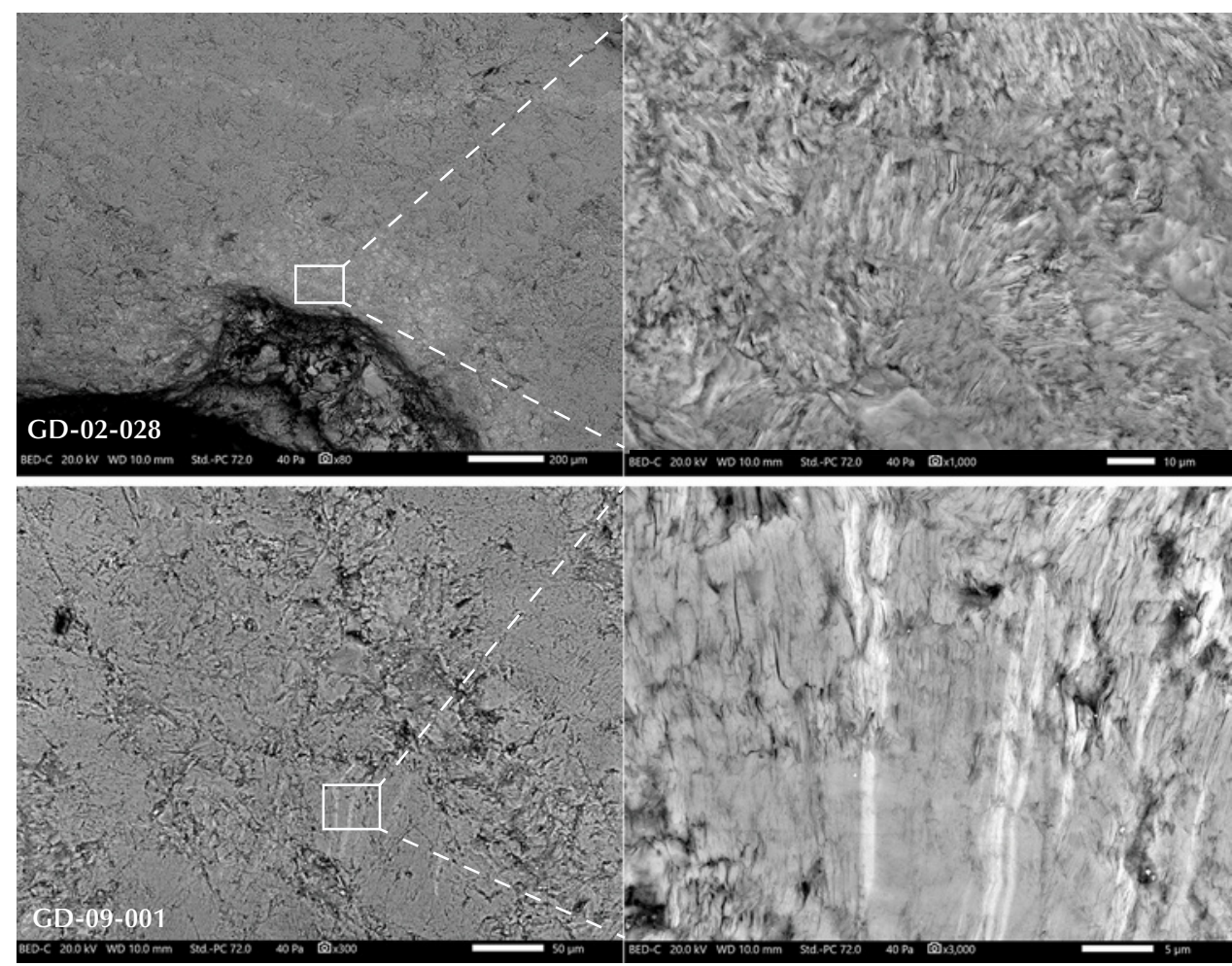

Figure 6. SEM-BSE images show lighter sheets in areas of some artifacts, revealing slight changes in the chemical composition toward heavier elements (artifacts GD-02028 and GD-09-001). Images by Yannick Lefrais. 


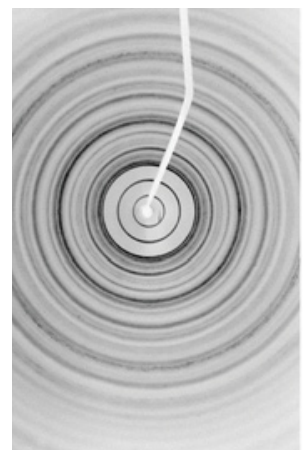

GD-01-017

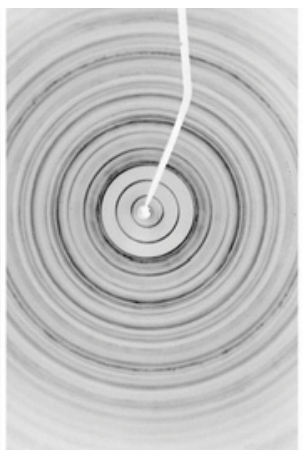

GD-01-020

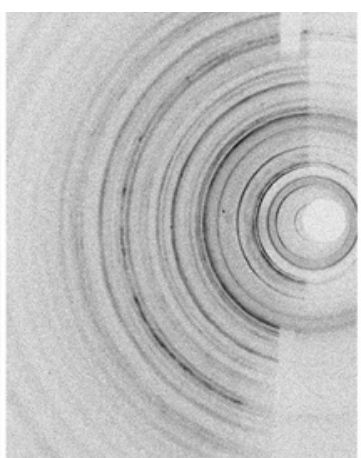

GD-02-028

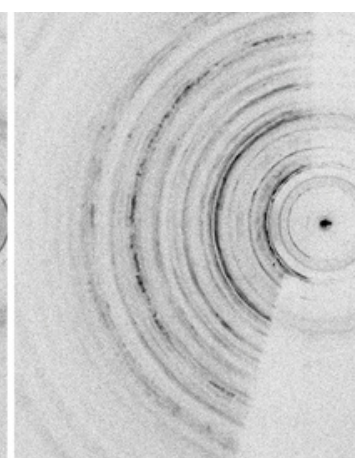

GD-01-019

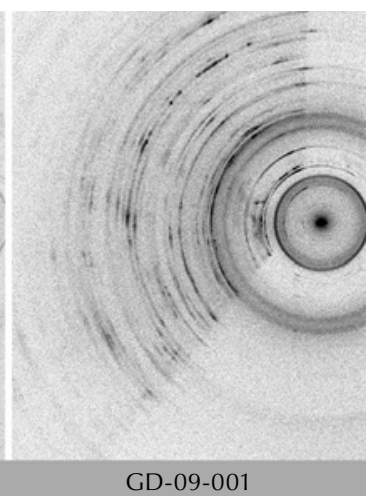

GD-09-001

Figure 7. Diffraction patterns (from image plate) obtained in transmission (GD-01-017 and GD-01-020) and lowangle reflection mode (GD-01-019, GD-02-028, and GD-09-001). The observation of complete Debye-Scherrer rings rather than just dots demonstrates the polycrystalline character of the samples, including some preferential orientation leading to darker points.

fraction pattern are mentioned: smaller $\mathrm{d}(060)$ values for sudoite (listed as $1.515 \AA$ in table 4 of their work) than clinochlore $(1.52-1.56 \AA)$, a d(001) value "slightly smaller" for sudoite, and a "more intense" peak for the (003) reflection (observed near $4.70 \AA$ ) in the sudoite pattern. As for our artifacts, we were able to measure $\mathrm{d}(060)$ values of $1.518 \AA$ (GD-01-017), $1.509 \AA$ (GD-01-019), $1.515 \AA$ (GD-01-020), $1.507 \AA$

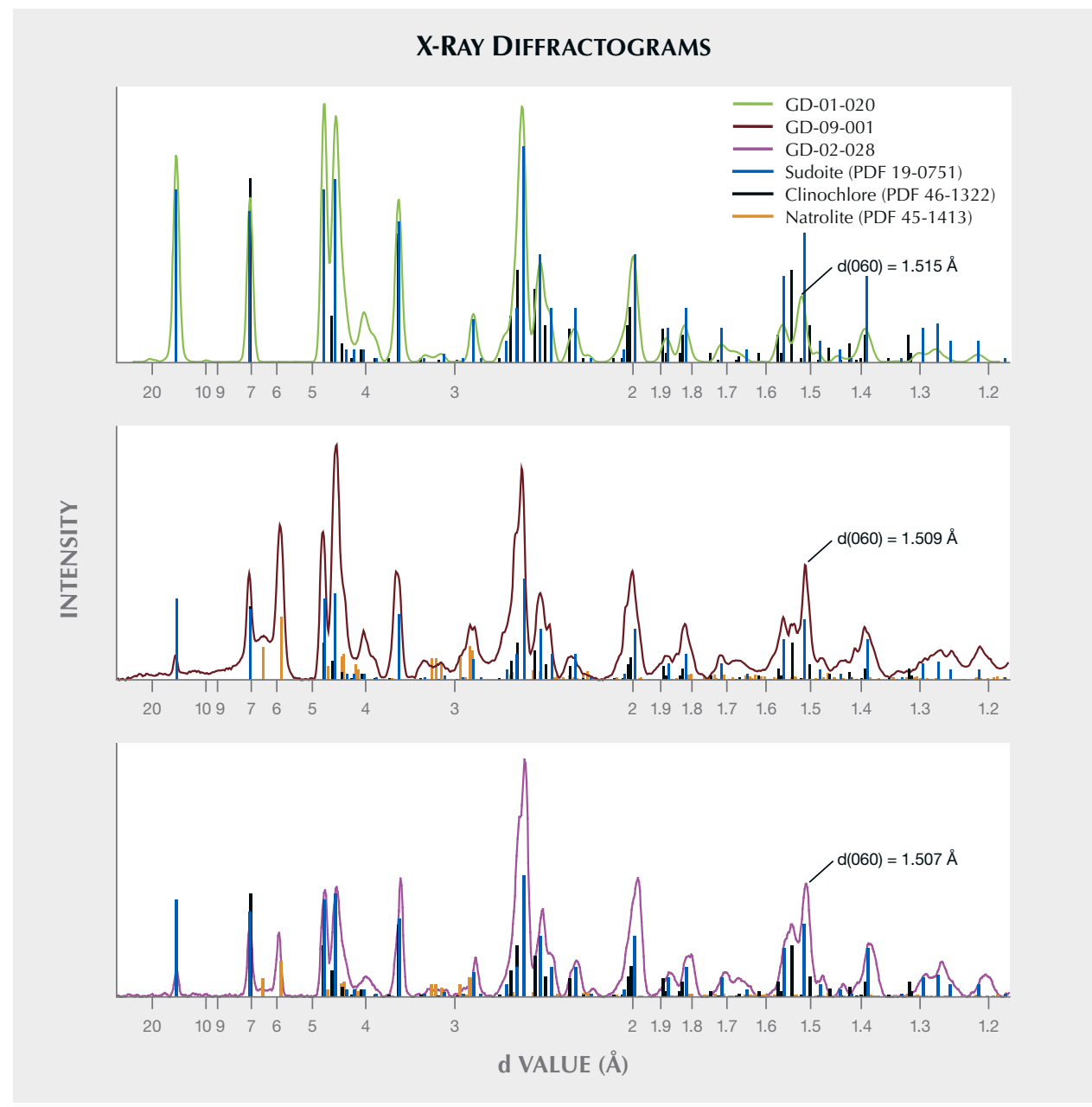

Figure 8. Diffractograms obtained on three of the five Amerindian artifacts, in transmission or lowangle mode. Sudoite diffraction pattern PDF 19-0751 fits better than clinochlore, especially for the d(060). Note the presence of natrolite in different proportions. Note also that the $x$ axis is logarithmic. 


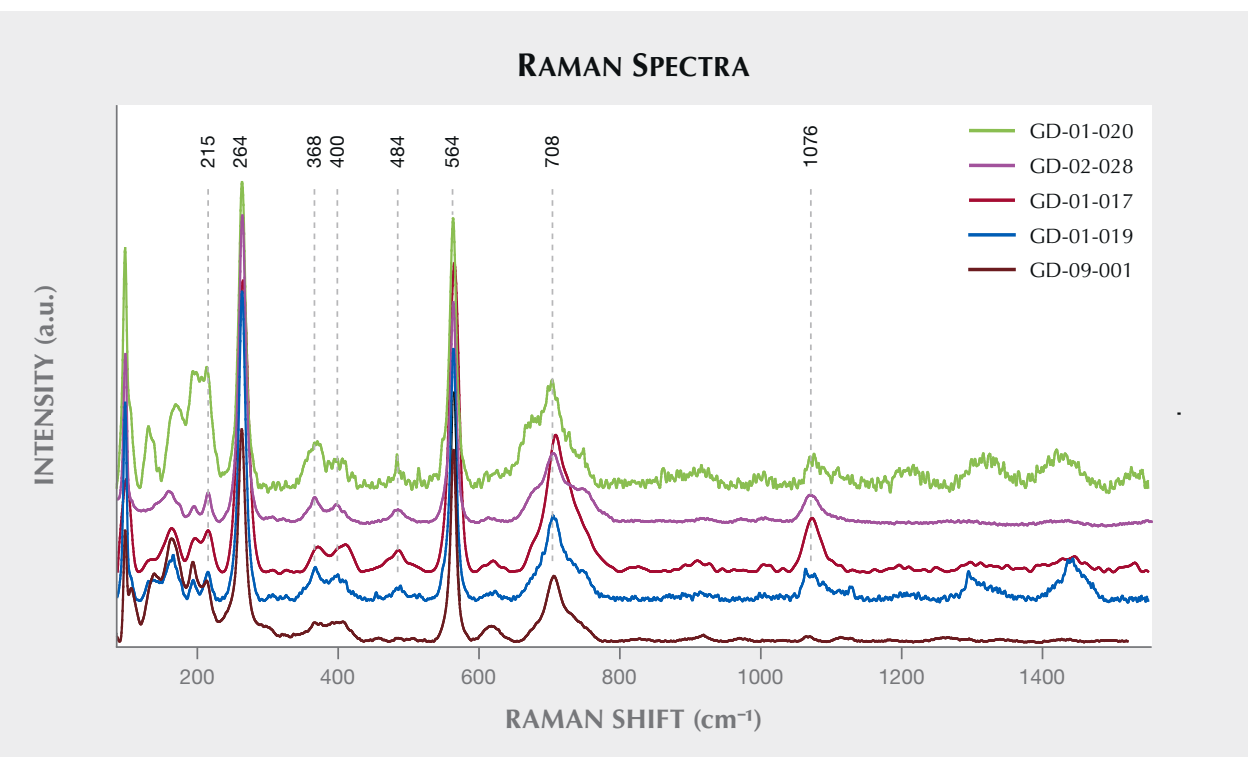

Figure 9. Raman spectra showing the consistency of the measurements from different samples. Spectra are offset vertically for clarity.

(GD-02-028), and $1.509 \AA$ (GD-09-001). We also observed a very intense (003) reflection in most samples, but our measurements were obtained on massive samples and not powder, so the relative intensity of the peaks cannot be considered representative. Therefore, the data obtained strongly suggest identification of sudoite, and the presence of accessory clinochlore may explain some shoulders and the peak at $1.535 \AA$ (e.g., sample GD-09-001).

This X-ray method probes a larger volume than the very small volume excited by the laser in Raman microspectroscopy. This resulted in the identification of an additional mineral for three of the samples (GD-01-019, GD-02-028, and GD-09-001), namely natrolite $\mathrm{Na}_{2}\left(\mathrm{Al}_{2} \mathrm{Si}_{3} \mathrm{O}_{10}\right) \cdot 2 \mathrm{H}_{2} \mathrm{O}$, which is a mineral of the zeolite family (figure 8). Natrolite was not identified at the microscopic scale with Raman spectroscopy (figure 10B). The proportion of this mineral, which is highly variable, is difficult to estimate without a Rietveld refinement, which cannot be achieved with our mode of measurement.

Vibrational Spectroscopy. Raman spectroscopy, the only method applied to all the artifacts presented in this study, illustrates the homogeneity of the composition of these different lapidary objects (figure 9). These results were obtained with desktop equipment on five artifacts. The other four objects were identified as made of the same material, with analysis carried out in museums and other curatorial sites using a portable Raman spectrometer (not shown). A very good agreement can be observed between our results and the only published spectrum for the mineral sudoite (Reynard et al., 2015) (figure 10A), with a cor- respondence of peak positions not observed with the more common mineral of the chlorite family, clinochlore (figure 10B). Sudoite is positively identified through sharp and intense bands at 264 and 564 $\mathrm{cm}^{-1}$. The bands located between $3300-3600 \mathrm{~cm}^{-1}$ and $3600-3800 \mathrm{~cm}^{-1}$ originate from vibrations of the $\mathrm{Al}-\mathrm{OH}$ and $(\mathrm{Mg}, \mathrm{Fe})-\mathrm{OH}$ bonds, respectively (Reynard et al., 2015). Analyzing multiple points on the surface of the archaeological artifacts led to the recognition of rare clinochlore grains, which are probably accessory minerals (as already suggested by XRD characterization), and also of some gypsum, probably the result of pollution on the surface of the samples, which were excavated from coastal sediments.

Infrared spectroscopy (figure 11) confirmed the attribution of the material to the di-trioctahedral chlorite group based on the spectral features in the region of the hydroxyl bond vibrations: The band at 3584 $\mathrm{cm}^{-1}$ originates from vibrations of the $(\mathrm{Mg}, \mathrm{Fe})-\mathrm{OH}$ bonds, while the presence of two wide bands in the $3300-3500 \mathrm{~cm}^{-1}$ region is interpreted as two different $\mathrm{OH}-\mathrm{O}$ distances in the interlayer hydroxyl sheets and thus distinctive of the di-trioctahedral structure (Farmer, 1974; Shirozu and Ishida, 1982; Madejová et al., 2017). The characteristic splitting of the Si-O stretching band around $1000 \mathrm{~cm}^{-1}$ in clinochlore, which is absent from our measurements, also supports the identification as sudoite (Madejová et al., 2017). Because of the shape and fragility of the objects, some spectra were difficult to obtain, particularly for the small bead GD-01-020. Comparison with spectra from the literature shows a shift of the main bands in the $400-1200 \mathrm{~cm}^{-1}$ region by approximately $30 \mathrm{~cm}^{-1}$. The sharp band at $830 \mathrm{~cm}^{-1}$, attrib- 


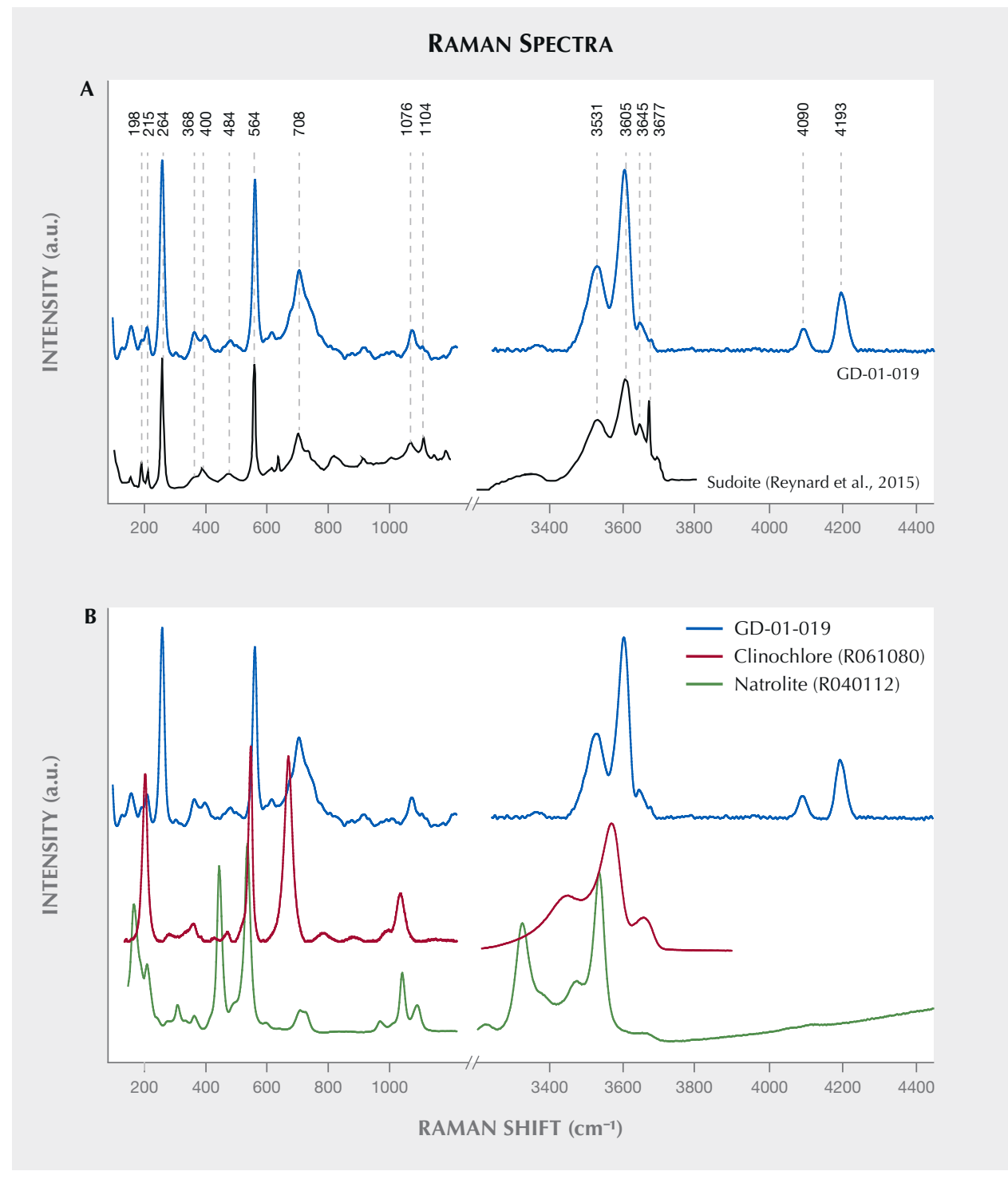

Figure 10. A: Comparison between the Raman spectra obtained on artifact GD-01-019 and the sudoite spectrum determined by Reynard et al. (2015, figure 1). B: Comparison between the Raman spectra obtained on artifact GD-01-019 and reference spectra for clinochlore and natrolite from the RRUFF database (Lafuente et al., 2016). Spectra are offset vertically for clarity.

uted to the (SiAl)OOH bond (Farmer, 1974), however, shows agreement between our experiment and the literature and therefore seems to rule out measurement artifacts. Discrepancies between the data from the literature and our measurements for the archaeological artifacts remain to be explained.

Chemical Characterization. A high degree of chemical homogeneity was observed in EDXRF analysis (figure 12). The major elements are clearly $\mathrm{Mg}, \mathrm{Al}$, and $\mathrm{Si}$, consistent with the formula of sudoite, especially taking into account the low efficiency expected for light elements with this method. We also noted the presence of impurities such as $\mathrm{P}, \mathrm{S}, \mathrm{Cl}, \mathrm{K}, \mathrm{Ca}$, Ti, $\mathrm{V}, \mathrm{Fe}$, and $\mathrm{Zn}$, as well as very low contents of $\mathrm{Mn}$ and $\mathrm{Ga}$. The argon (Ar) peak is an artifact related to air in the measured volume.
SEM-EDS analyses provide quantification in good agreement with the theoretical composition of sudoite (table 4) and with the published chemical compositions for different sudoite samples from around the world (table 5). Comparative chemical analysis of the light and dark laminae observed in the BSE image shows a higher potassium and/or barium content, correlated with a decrease in magnesium for the light gray sheets (table 6 ). The balance of charges, modified by potassium $(1+)$ instead of magnesium $(2+)$, is compensated by a decrease in aluminum $(3+)$ in favor of silicon (4+). The composition of the light gray sheets could approach a mixed composition between sudoite and illite, which would be consistent with the possible presence of illite, a mineral often associated with sudoite (Billault et al., 2002; Ruiz Cruz and de Galdeano, 2005). Mixed layers of sudoite with other phyllosili- 


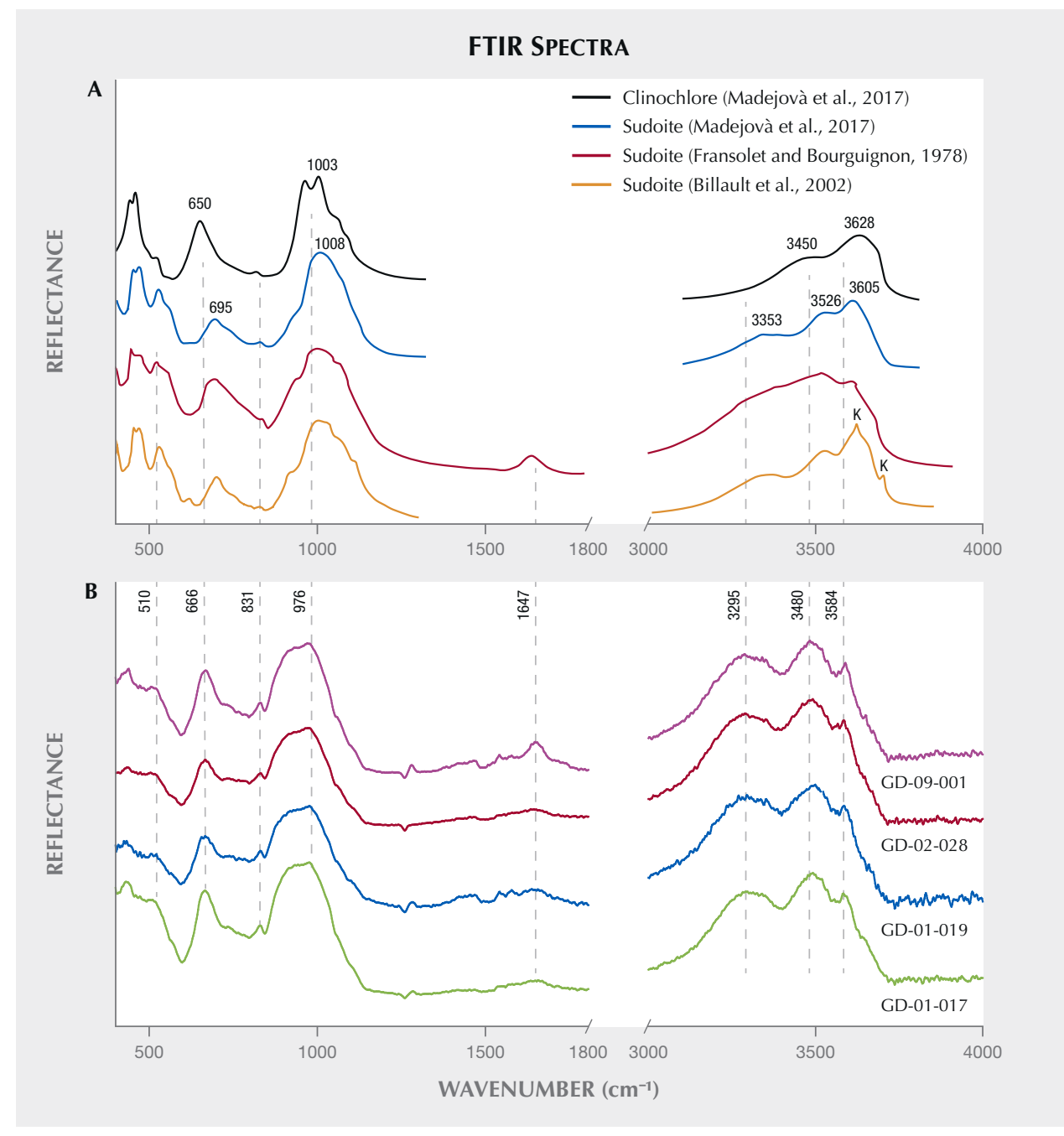

Figure 11. Clinochlore and sudoite FTIR spectra reported in the literature $(A)$ and measured ATR-mode spectra from archaeological artifacts (B). K represents kaolinite (Billault et al., 2002). Spectra are offset vertically for clarity.

cates have been observed in Transmission electron

Galdeano, 2005). However, the observation and measmicroscope (TEM) analysis (Ruiz Cruz and de urement parameters used during the SEM analysis, op-

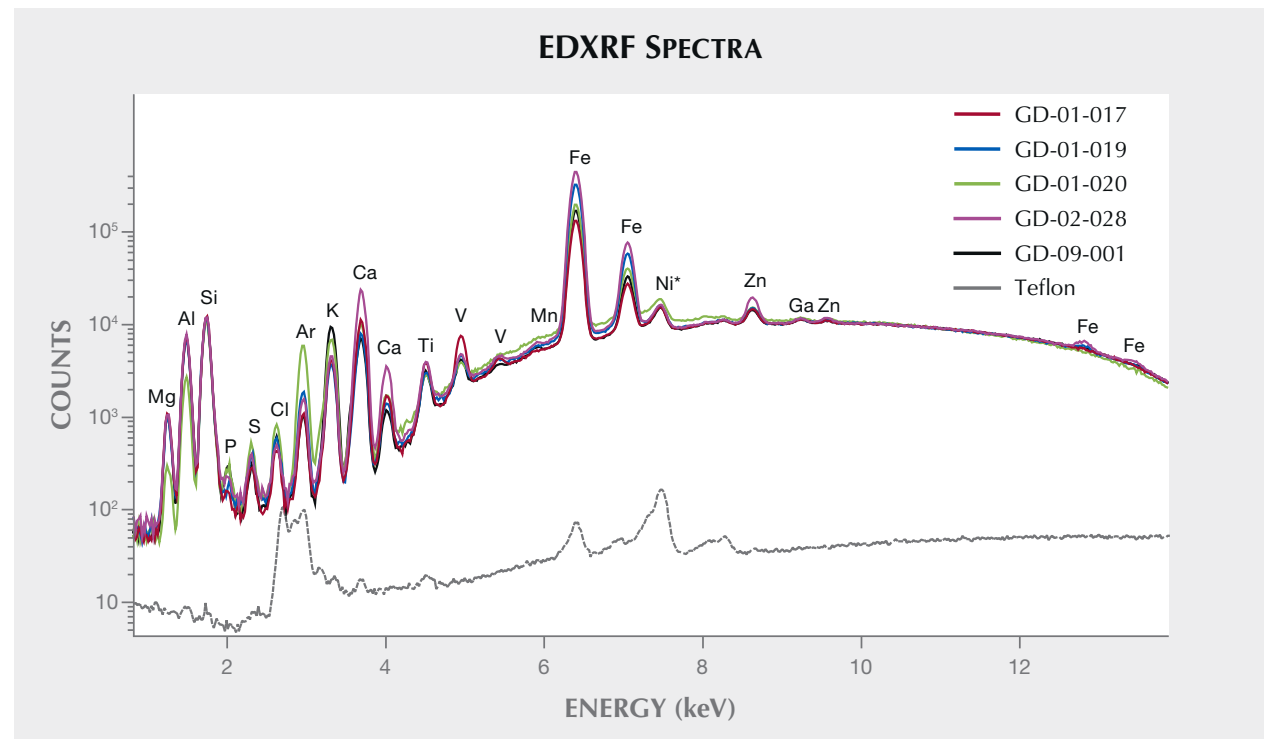

Figure 12. EDXRF spectra obtained on the five exported artifacts with identified peaks. The lower spectrum is for Teflon, measured as a blank. The Ni peak labeled with an asterisk is from the device. The intensity is displayed in logarithmic scale for better clarity of the entire signal, especially for the light elements. 
TABLE 4. Chemical composition for different sites on each sudoite artifact, measured with SEM-EDS (SD standard deviation on three measurements) under low-vacuum conditions.

\begin{tabular}{|c|c|c|c|c|c|c|c|c|c|c|c|c|c|c|c|c|c|}
\hline Measurement site & & $\mathrm{O}+\mathrm{OH}$ & $\mathrm{Na}$ & $\mathrm{Mg}$ & $\mathrm{Al}$ & Si & $\mathbf{P}$ & S & $\mathrm{Cl}$ & K & $\mathrm{Ca}$ & $\mathrm{Ti}$ & V & Mn & $\mathrm{Fe}$ & $\mathrm{Sr}$ & $\mathrm{Ba}$ \\
\hline \multirow[t]{2}{*}{ GD 02-028/Site 1} & Mean & 18 & 0.04 & 1.88 & 3.78 & 3.04 & 0.01 & bql & bql & 0.04 & 0.01 & bql & bdl & bdl & 0.19 & bdl & bdl \\
\hline & SD & - & 0.01 & 0.05 & 0.02 & 0.04 & $<0.01$ & - & - & 0.01 & 0.01 & - & - & - & 0.01 & - & - \\
\hline \multirow[t]{2}{*}{ GD 02-028/Site 2} & Mean & 18 & 0.04 & 2.47 & 3.42 & 2.55 & 0.01 & 0.01 & bql & 0.21 & 0.02 & bdl & bdl & bql & 0.25 & 0.01 & 0.01 \\
\hline & SD & - & 0.01 & 0.16 & 0.04 & 0.05 & $<0.01$ & $<0.01$ & - & 0.07 & 0.01 & - & - & - & 0.02 & 0.01 & 0.01 \\
\hline \multirow[t]{2}{*}{ GD 01-019/Site 1} & Mean & 18 & 0.02 & 1.68 & 3.44 & 3.63 & 0.01 & bql & 0.01 & 0.05 & 0.03 & bql & bdl & bdl & 0.12 & bdl & bdl \\
\hline & SD & - & 0.01 & 0.07 & 0.10 & 0.15 & $<0.01$ & - & $<0.01$ & 0.02 & 0.01 & - & - & - & $<0.01$ & - & - \\
\hline \multirow[t]{2}{*}{ GD 01-019/Site 3} & Mean & 18 & 0.03 & 1.98 & 3.72 & 3.02 & 0.02 & 0.01 & bql & 0.02 & 0.02 & $\mathrm{bql}$ & bdl & bdl & 0.16 & bdl & bdl \\
\hline & SD & - & 0.00 & 0.13 & 0.07 & 0.05 & 0.01 & $<0.01$ & 0.01 & 0.01 & 0.01 & - & - & - & 0.01 & - & - \\
\hline \multirow[t]{2}{*}{ GD 01-020/Site 1} & Mean & 18 & 0.08 & 1.55 & 3.37 & 3.60 & 0.04 & 0.01 & 0.02 & 0.12 & 0.10 & 0.01 & bdl & bdl & 0.11 & bdl & bdl \\
\hline & SD & - & 0.02 & 0.13 & 0.18 & 0.21 & 0.01 & $<0.01$ & 0.01 & 0.03 & 0.03 & $<0.01$ & - & - & $<0.01$ & - & - \\
\hline \multirow[t]{2}{*}{ GD 01-020/Site 2} & Mean & 18 & 0.05 & 1.80 & 3.60 & 3.24 & 0.02 & bql & 0.01 & 0.12 & 0.04 & bdl & bdl & bdl & 0.12 & bdl & bdl \\
\hline & SD & - & 0.02 & 0.08 & 0.09 & 0.08 & 0.01 & - & 0.01 & 0.03 & 0.01 & - & - & - & 0.01 & - & - \\
\hline \multirow[t]{2}{*}{ GD 01-017/Site 1} & Mean & 18 & 0.02 & 1.97 & 3.82 & 3.07 & 0.01 & 0.01 & bql & 0.05 & 0.01 & $\mathrm{bql}$ & bql & bdl & 0.05 & bdl & bdl \\
\hline & SD & - & $<0.01$ & 0.04 & 0.02 & 0.03 & $<0.01$ & $<0.01$ & - & 0.02 & $<0.01$ & - & - & - & $<0.01$ & - & - \\
\hline \multirow[t]{2}{*}{ GD 01-017/Site 2} & Mean & 18 & 0.02 & 1.93 & 3.75 & 3.10 & 0.01 & 0.01 & 0.01 & 0.05 & 0.05 & $\mathrm{bql}$ & bql & bdl & 0.06 & bdl & bdl \\
\hline & SD & - & $<0.01$ & 0.04 & 0.03 & 0.03 & $<0.01$ & $<0.01$ & $<0.01$ & 0.01 & 0.02 & - & - & - & 0.01 & - & - \\
\hline \multirow[t]{2}{*}{ GD 09-001/Site 1} & Mean & 18 & 0.02 & 1.90 & 3.80 & 3.08 & 0.01 & 0.01 & 0.01 & 0.07 & 0.02 & bql & bdl & bdl & 0.08 & bdl & bdl \\
\hline & SD & - & $<0.01$ & 0.02 & 0.01 & 0.01 & $<0.01$ & $<0.01$ & $<0.01$ & 0.01 & $<0.01$ & - & - & - & $<0.01$ & - & - \\
\hline \multirow[t]{2}{*}{ GD 09-001/Site 3} & Mean & 18 & 0.03 & 1.71 & 3.74 & 3.20 & 0.02 & 0.01 & 0.01 & 0.17 & 0.03 & $\mathrm{bql}$ & bdl & bdl & 0.08 & bdl & bdl \\
\hline & SD & - & 0.01 & 0.13 & 0.06 & 0.08 & 0.02 & - & 0.01 & 0.08 & 0.02 & - & - & - & 0.03 & - & - \\
\hline
\end{tabular}

Values in atoms per formula unit normalized to an anionic composition of $\mathrm{O}_{10}(\mathrm{OH})_{8}$. bql = below quantification limit. bdl = below detection limit $(<0.01$ atom $\%)$.

timized for well-focused images of the structure in low-vacuum conditions, did not make it possible to measure only the very thin light gray sheets. Indeed, Monte Carlo simulations indicate that the volume analyzed would be 3-4 $\mu \mathrm{m}$ wide and 3.0-3.5 $\mu \mathrm{m}$ deep.

The natrolite phase, identified by X-ray diffraction in samples GD-09-001, GD-02-028, and GD-01-019, was not identified during the SEM analysis, based on either morphological or chemical data. A few massive grains, lacking any sheet structure, were analyzed, revealing a slightly different chemistry. They were richer in sodium and silicon, with less magnesium and aluminum, but still far from the composition of natrolite (table 5). The analyzed volume given the parameters used (3-4 $\mu \mathrm{m}$ wide and 3.0-3.5 $\mu \mathrm{m}$ deep), being unfortunately larger than the grains themselves $(1.0-1.5 \mu \mathrm{m})$, prevents us from being conclusive about this. Nevertheless, those grains were very few in number in the artifacts and do not seem to explain the significant diffraction peaks for this mineral phase when present. It is, however, possible that a more in-depth examination of the artifacts ex- 
TABLE 5. Mean composition of the archaeological assemblage, compared with the theoretical composition of sudoite (from IMA), with the experimental composition from the literature (Bailey and Lister, 1989; Ruiz Cruz and de Galdeano, 2005), and with theoretical clinochlore and natrolite.

\begin{tabular}{|c|c|c|c|c|c|c|c|c|c|c|}
\hline & & $\mathrm{O}+\mathrm{OH}$ & $\mathrm{Na}$ & $M g$ & Al & $\mathrm{Si}$ & K & $\mathrm{Ca}$ & Mn & $\mathrm{Fe}$ \\
\hline \multirow{2}{*}{$\begin{array}{l}\text { Archaeological } \\
\text { samples }\end{array}$} & Mean & 18 & 0.03 & 1.90 & 3.65 & 3.15 & 0.08 & 0.03 & bql & 0.12 \\
\hline & SD & - & 0.02 & 0.24 & 0.18 & 0.30 & 0.06 & 0.03 & - & 0.06 \\
\hline \multicolumn{2}{|c|}{ Theoretical sudoite } & 18 & & 2 & 4 & 3 & & & & \\
\hline \multicolumn{2}{|c|}{ Mean (Bailey and Lister, 1989) } & 18 & 0.07 & 1.81 & 3.81 & 3.11 & 0.06 & 0.08 & 0.02 & 0.14 \\
\hline & SD & - & 0.07 & 0.34 & 0.26 & 0.15 & 0.06 & 0.05 & 0.01 & 0.12 \\
\hline \multicolumn{2}{|c|}{$\begin{array}{r}\text { Mean (Ruiz Cruz and de } \\
\text { Galdeano, 2005) }\end{array}$} & 18 & 0.12 & 1.80 & 3.82 & 3.10 & 0.05 & $b q l$ & bql & 0.25 \\
\hline & SD & - & 0.09 & 0.17 & 0.04 & 0.08 & 0.02 & - & - & 0.04 \\
\hline \multicolumn{2}{|c|}{ Theoretical clinochlore } & 18 & & 5 & 2 & 3 & - & - & - & - \\
\hline \multicolumn{2}{|c|}{ Theoretical natrolite } & 12 & 2 & & 2 & 3 & - & - & - & - \\
\hline
\end{tabular}

hibiting natrolite by XRD could reveal the distribution and structure of this zeolite mineral.

Origin of Color and UV Luminescence. The visible absorption spectra show a continuum of absorption in the violet and the blue; a very wide, shallow transmission band in the green; and absorption rising in the orange and red that is sample-dependent but always greater than in the green (figure 13A). This ex- plains the observed overall green color component in these objects, as described by Fransolet and Bourguignon (1978). The spectra obtained are also quite close to those of other chlorite group minerals analyzed in the literature (Bishop et al., 2008), although it is not clear whether the $\mathrm{Fe}^{2+}-\mathrm{Fe}^{3+}$ charge transfer is involved with the bands delimiting the transmission window. The relatively sharp band at $375 \mathrm{~nm}(26666$ $\mathrm{cm}^{-1}$ ) could be attributed to $4 \mathrm{E}(\mathrm{D})$ spin-forbidden

TABLE 6. Composition of the lighter sheets observed on the backscattered electron image (figure 6), compared to the composition of the illite sheets analyzed by Ruiz Cruz and de Galdeano (2005).

\begin{tabular}{|c|c|c|c|c|c|c|c|c|c|c|}
\hline Measurement location & Spectra & $\mathrm{O}+\mathrm{OH}$ & $\mathrm{Na}$ & $\mathrm{Mg}$ & $\mathrm{Al}$ & $\mathrm{Si}$ & $\mathrm{K}$ & $\mathrm{Ca}$ & $\mathrm{Fe}$ & $\mathrm{Ba}$ \\
\hline GD-02-028/Site 2 & 6 & 12 & 0.04 & 0.50 & 2.67 & 2.37 & 0.55 & 0.03 & 0.06 & 0.04 \\
\hline GD-02-028/Site 2 & 7 & 12 & 0.04 & 0.59 & 2.65 & 2.33 & 0.51 & 0.03 & 0.07 & 0.03 \\
\hline GD-09-001/Site 4 & 42 & 12 & 0.01 & 0.73 & 2.43 & 2.63 & 0.39 & 0.01 & 0.03 & bdl \\
\hline GD-09-001/Site 4 & 43 & 12 & 0.01 & 0.67 & 2.42 & 2.69 & 0.42 & 0.01 & 0.03 & bdl \\
\hline $\begin{array}{l}\text { Mean illite (Ruiz Cruz and } \\
\text { de Galdeano, 2005) }\end{array}$ & - & 12 & 0.26 & 0.13 & 2.65 & 3.27 & 0.65 & - & 0.06 & - \\
\hline Standard deviation & - & - & 0.21 & 0.05 & 0.16 & 0.12 & 0.19 & - & 0.03 & - \\
\hline
\end{tabular}




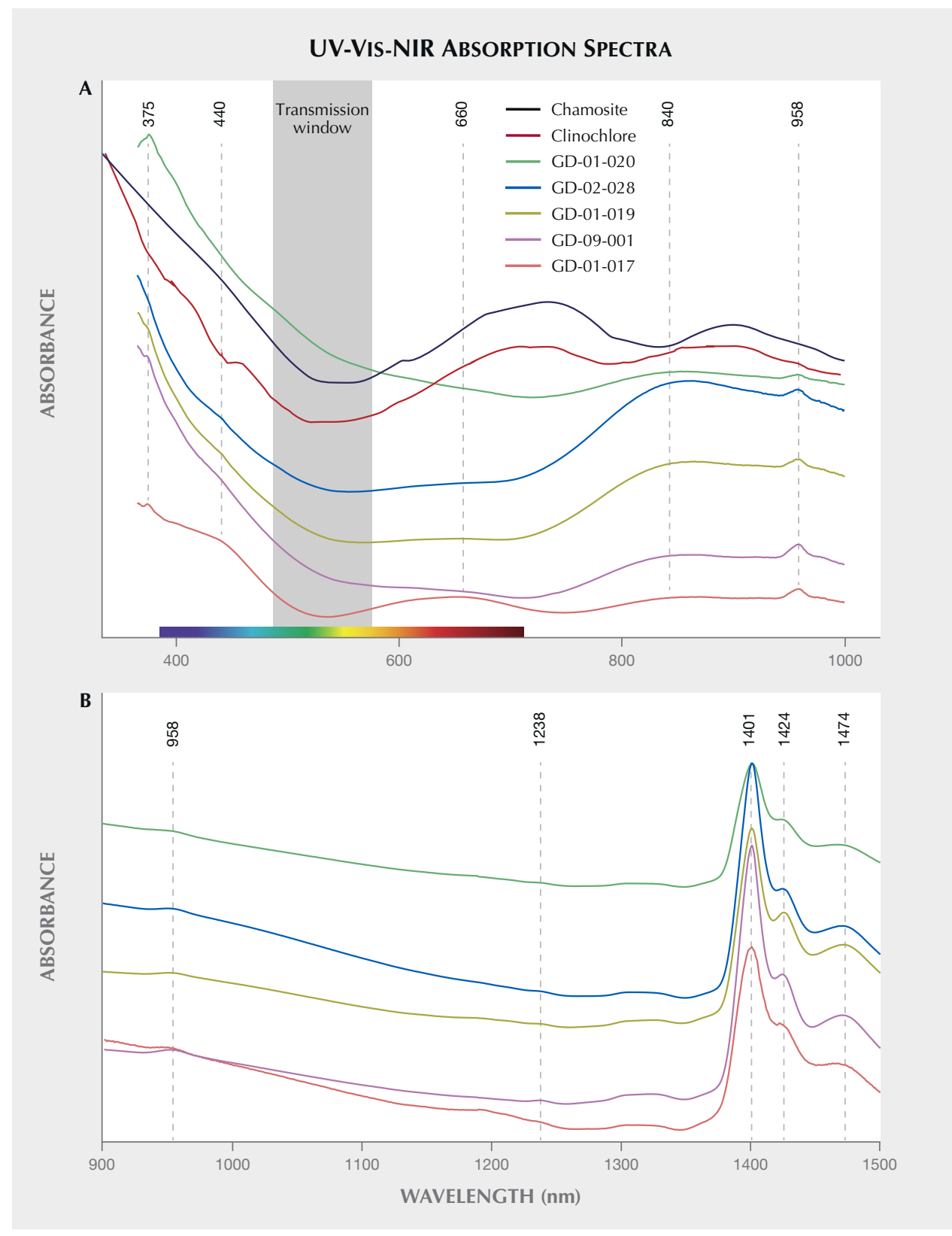

Figure 13. UV-Vis-NIR absorption spectra measured on the archaeological samples with the GemmoSphere instrument $(A)$ and the Perkin Elmer instrument (B). The spectra for clinochlore and chamosite are from Bishop et al. (2008, figure 6). Spectra are offset vertically for clarity.

transitions of isolated $\mathrm{Fe}^{3+}$ (Krebs and Maisch, 1971; Palanza et al., 2010). The continuum from the UV into the visible region is thus likely related to the $\mathrm{O}^{2-}-\mathrm{Fe}^{3+}$ charge transfer, and it explains the brownish yellow color component in some samples. The wide bands around 440 and $660 \mathrm{~nm}$ vary together, and may correspond with the position of the bands of $\mathrm{V}^{3+}$ absorption as proposed for vanadium-doped glass by Johnston (1965, figure 1) and Wang et al. (2015). They are indeed the most important for the samples containing the most vanadium (figure 12 and table 4). While the $\mathrm{Fe}^{2+}-\mathrm{Fe}^{3+}$ transitions could also have been a candidate for one of these bands, the variation in intensity of the broad absorption bands does not correlate with the concentration levels of this element, and their position is not similar to the band reported in the literature at around $710 \mathrm{~nm}\left(14100 \mathrm{~cm}^{-1}\right)$ for chlorite (Mattson and Rossman, 1987). However, Mattson and Rossman (1987) also indicate that the position of absorption bands due to $\mathrm{Fe}^{2+}-\mathrm{Fe}^{3+}$ charge transfer is highly variable. It is interesting to note that the value of $710 \mathrm{~nm}$ would, on the other hand, correspond very well to wide bands observed in clinochlore and chamosite, two other minerals from the chlorite group. The wide band in the near-infrared, around $830-850 \mathrm{~nm}$ and extending well into 


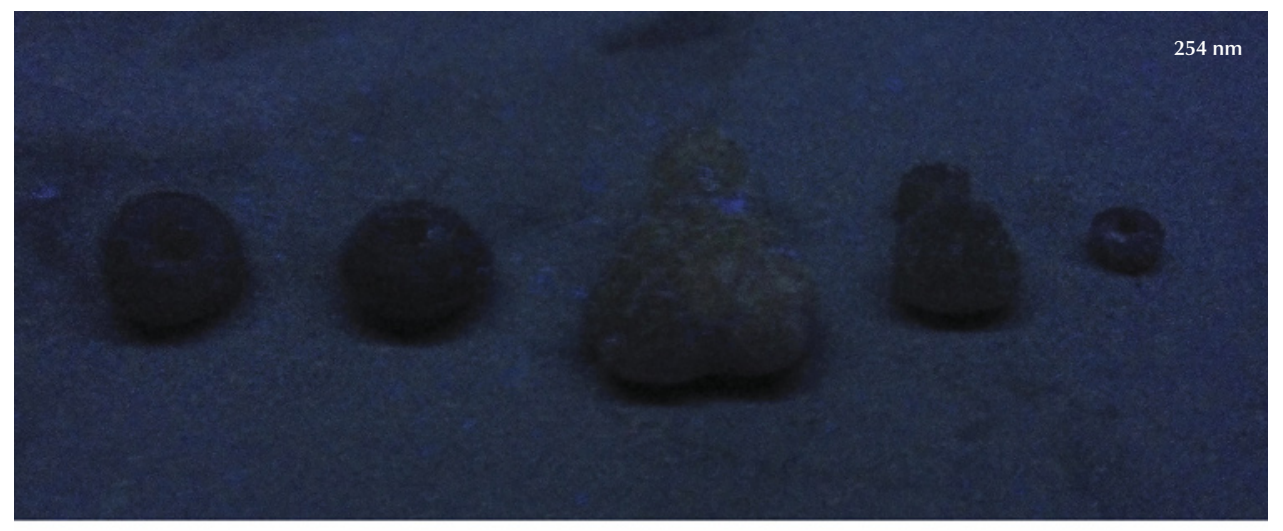

GD-01-019 GD-02-028 GD-09-001

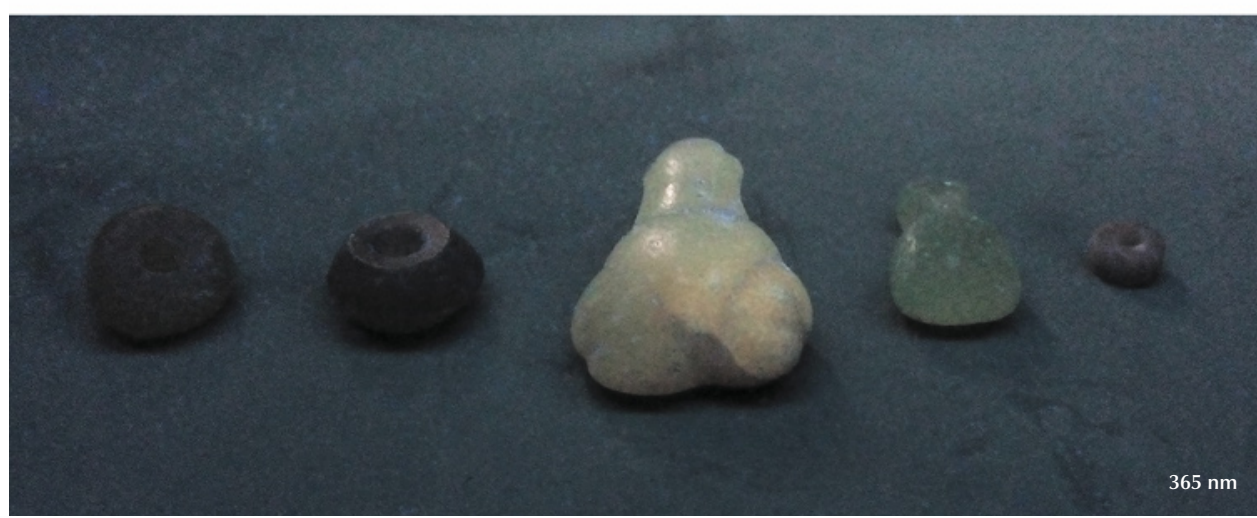

Figure 14. Luminescence of the sudoite samples under shortwave (top) and longwave (bottom) UV light. Photos by Alain Queffelec. the visible range, could be attributed to $\mathrm{Fe}^{2+}$ in octahedral position (Spinolo et al., 2007), its intensity correlating with the iron content observed using EDXRF (figure 12) and SEM-EDS (table 4). Thus the transmission window is essentially due to iron: on the UV side essentially by the $\mathrm{O}^{2-}-\mathrm{Fe}^{3+}$ charge transfer, and on the red side by $\mathrm{Fe}^{2+}$, with modulation by some $\mathrm{V}^{3+}$

Finally, water vibrations explain the $958 \mathrm{~nm}$ band, as well as absorptions at 1424 and $1474 \mathrm{~nm}$ (figure 13B), while O-H bond stretching corresponds to the $1401 \mathrm{~nm}$ band (Hunt, 1977; Clark et al., 1990; Clark, 1999; Bishop et al., 2008). These absorption bands could also be interpreted as the water vibrations in the natrolite structure because of their similarity with the spectra obtained by Clark et al. (1990) for this mineral. The absorptions between 1400 and $1500 \mathrm{~cm}^{-1}$ are actually the most intense for samples GD-01-019, GD-02-028, and GD-09-001, which are the three samples exhibiting the most intense natrolite X-ray diffraction peaks.

Figure 14 and table 3 group the ultraviolet luminescence observations. Under short-wave UV light, none of the five objects tested show significant luminescence. Under long-wave UV light, three of the five objects tested are homogeneously luminescent, with low to moderate intensity, and show a green to greenyellow color. None show any phosphorescence.

Since the strongest long-wave UV luminescence was observed for samples GD-09-001 and GD-01-017 (figure 14), these two artifacts were also subjected to spectrofluorimetric measurements (figure 15). Note that it is indeed the two samples with the lowest iron content that show this luminescence, as is often the case due to the luminescence quenching character of iron, linked to the $\mathrm{O}^{2-}-\mathrm{Fe}^{3+}$ charge transfer (Fritsch and Waychunas, 1994). The emission spectrum with 420 $\mathrm{nm}$ excitation is very similar for the two artifacts (figure 15, A and B), suggesting a common origin. The spectrum is asymmetrical, wider on the red side, with probably several components. The maximum is located around $525 \mathrm{~nm}$ in the green. Yet the emission covers the entire visible spectrum, inducing a whitish color appearance. The greater sensitivity of the human eye to green wavelengths than blue wavelengths, combined with the color of the object itself that may be seen through the luminescence, results in an observed luminescence color of green-yellow. The 3D spectra obtained on the most luminescent object, GD-09-001, indicate that the luminescence reaches a maximum at $435 \mathrm{~nm}$. Wavelengths lower than $420 \mathrm{~nm}$ could not be tested because the measured emission spectrum 


\section{LUMINESCENCE EMISSION SPECTRA}
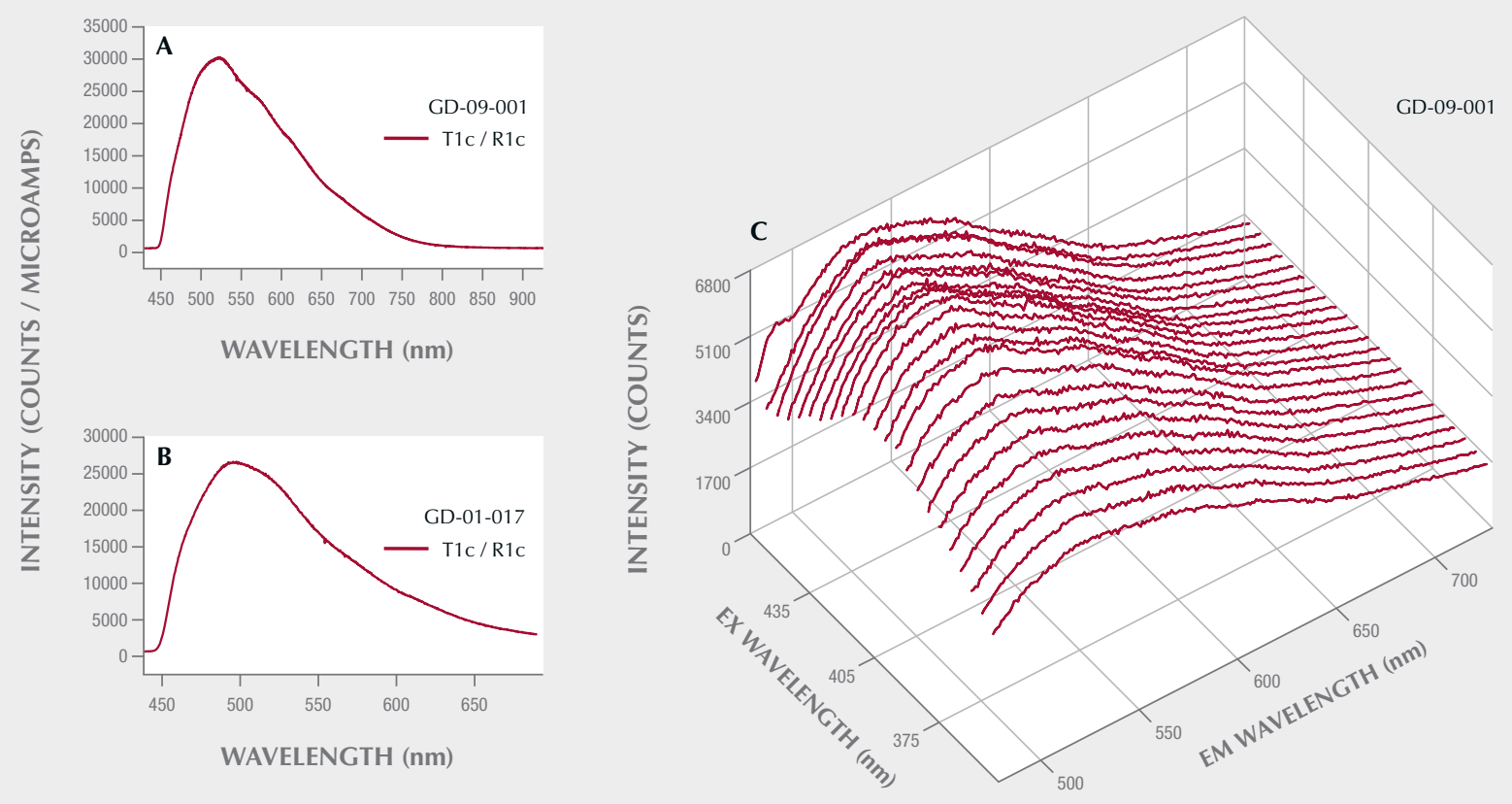

Figure 15. A and B: Luminescence emission spectra with $420 \mathrm{~nm}$ excitation for GD-09-001 and GD-01-017, respectively. (T1c/R1c is the corrected intensity measured by the detector normalized to the corrected intensity of the emission source.) C: 3D luminescence spectra emitted by GD-09-001 for different excitation wavelengths.

starts at that point. The same 3D spectra were obtained for GD-01-017 (not shown), and the results were similar. This excitation maximum at $435 \mathrm{~nm}$ is somewhat reminiscent of the absorption maximum observed around $440 \mathrm{~nm}$ in UV-Vis-NIR spectroscopy, potentially attributed to vanadium. It is also the samples richest in vanadium that show the strongest absorption bands at 440 and $850 \mathrm{~nm}$ and exhibit this luminescence, but $\mathrm{V}^{3+}$ is not a common emitter and there are many other possibilities, such as a color center or another trace element ion. Although there are several emissions known for chlorites, the only cause of emission explicitly identified is $\mathrm{Cr}^{3+}$ (Gaft et al., 2005; Czaja et al., 2014).

\section{DISCUSSION}

Importance of the Multi-Analytical Approach. The identification of sudoite large enough to be carved deserves certain analytical efforts in order to unambiguously confirm its mineralogical nature. To this end, several types of analysis (physical, chemical, and structural) have been cross-matched. A more common mineral from the chlorite group, whose similar characteristics could lead to confusion with sudoite, is clinochlore. In particular, its X-ray diffractogram is similar to that of sudoite, and it would have been very difficult to formally exclude it, especially given the particular measurement conditions required by archaeological samples. It was possible, though, to rule out clinochlore thanks to the results of vibrational and UV-Vis spectroscopy as well as elemental analyses that confirmed a composition matching that of sudoite. Raman spectra and the sheet structure could have led to a misidentification as pyrophyllite or muscovite on the basis of some main Raman bands, but the XRD, FTIR, and chemical analyses precluded this possible confusion. Clinochlore and natrolite are present as accessory minerals in some samples. The former is identified very rarely by Raman spectroscopy, as only a few points on the surface of the artifacts show clinochlore, and in XRD. The latter is present in the XRD pattern of some artifacts.

As a material used to produce lapidary artifacts, one could also be interested in its characterization by more classic gemological methods. Unfortunately, the polycrystalline nature, limited polish, and shape and size of the objects, as well as the absence of a non-archaeological reference material, have limited the possibilities of these approaches (e.g., the rather variable specific gravity and the difficulty of measuring the refractive index). The green color could be re- 


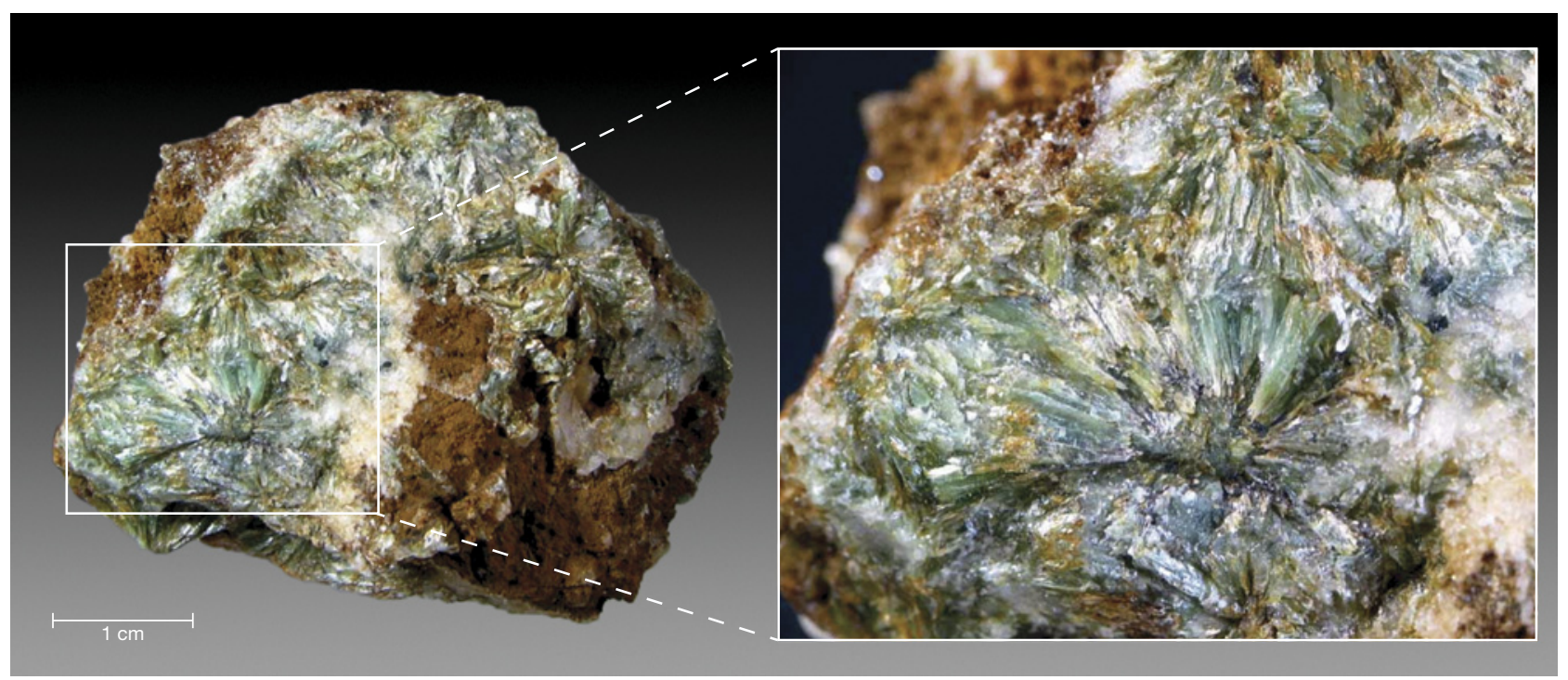

Figure 16. Photograph and microphotograph of a commercial sample of sudoite, showing the existence of centimeter-sized radial nodules. Courtesy of www.dakotamatrix.com.

lated to the sum of $\mathrm{Fe}^{3+}$, $\mathrm{Fe}^{2+}$, and $\mathrm{V}^{3+}$-related absorption bands, leaving mostly a shallow transmission window in the green. The UV luminescence of the material is documented for two samples, but its cause remains unclear.

Geological Origin. Sudoite has previously been identified in various geological contexts. The main type of rock in which sudoite is found has undergone lowtemperature/high-pressure metamorphism in a subduction context (Fransolet and Bourguignon, 1978; Goffé et al., 1988; Ruiz Cruz and de Galdeano, 2005). The stability field of sudoite is between 240 and $380^{\circ} \mathrm{C}$, and between 4 and 8 kbar (Goffé et al., 1988). In this context, it can come from an intermediate stage of metamorphism between a dickite assemblage and a chlorite + paragonite + chloritoid assemblage, in which it is found associated with pyrophyllite, which is not the case for our samples (Ruiz Cruz and de Galdeano, 2005). It may also result from retrograde metamorphism, as proposed in Oman, with a decrease in pressure synchronous with a slight increase in temperature (Goffé et al., 1988). Sudoite can form from kaolinite in the last stages of diagenesis, above $200^{\circ} \mathrm{C}$ (Daniels et al., 1990), and it is also encountered in a hydrothermal context, at temperatures higher than $200^{\circ} \mathrm{C}$ (Beaufort et al., 2015).

Sudoite is usually found in the form of fine clay (Billault et al., 2002; Lauf, 2010). Small rosettes up to $1 \mathrm{~mm}$ in diameter can form (Beaufort et al., 2015), as can scaly films (Gaines et al., 1997, cited in Lauf, 2010). Only one occurrence of centimeter-sized su- doite large enough to be carved could be found in the literature (figure 15 in Lauf, 2010), underscoring the rarity of such samples. Beaufort (2015) writes:

The only type of hydrothermal system in which sudoite has been reported in large amounts and in large volumes of altered rocks are unconformity-related uranium deposits (Percival and Kodama, 1989; Billault et al., 2002; Beaufort et al., 2005).

He more recently confirmed this to the authors: "With respect to ... sudoite occurrences in the Paleoproterozoic basins of Canada and Australia, the concept of massive can only be applied on a microscopic scale, because on a macroscopic scale this mineral is always associated with other clay minerals such as illite and kaolinite or dickite. To my knowledge, there is no gem sudoite in this type of geological context" (D. Beaufort, pers. comm., 2019). Rare largervolume samples consist of agglomerates of radial structures, with color and transparency close to those observed in the artifacts we studied (figure 16). They strongly resemble one studied and shown in, unfortunately, a poor-quality photograph (figure 2 in Jige et al., 2003). These agglomerates are also reminiscent of the structures observed by electron microscopy on sample GD-01-020 (figure 5).

\section{Provenance of the Antillean Archaeological Raw Ma-} terial. The tectonic context of the Caribbean presents high-pressure/low-temperature (HP/LT) metamorphic rocks, especially due to the numerous subduction zones (Garcia-Casco et al., 2011; see figure 17). The suture of these subduction zones produced ophi- 
olite (Garcia-Casco et al., 2006; Lewis et al., 2006), which can be the site of sudoite crystallization, as is the case in Oman (Goffé et al., 1988). Metapelites (metamorphic rocks resulting from the transformation of fine clay-rich sediments from the alteration of continental crust) subjected to a metamorphism of blueschist facies of low intensity can produce rocks containing magnesian chlorites and in particular sudoite (Goffé et al., 1988; Schreyer, 1988; Theye et al., 1992). Rocks formed under HP/LT conditions in the blueschist facies, common in the Caribbean and consistent with the presence of natrolite in some samples, would thus be an excellent candidate for the provenance of this material. It should also be noted that the morphology of the sudoite we observed under the electron microscope (figures 13 and 14) differs greatly from Canadian hydrothermal crystallizations (figure 2 in Billault et al., 2002). This criterion may also indicate that HP/LT metamorphism is more likely to be involved in the crystallization of sudoite than hydrothermal metamorphism.

The presence of sudoite in the Lesser Antilles adds to an existing set of converging clues in the mineralogy of gem materials used in Amerindian lapidary craftsmanship that indicate "long-distance" transport of the raw material. These raw materials, for which no precise source has been clearly stated, originate from rocks that do not naturally exist in the Lesser Antilles and must therefore come from the South American continent and/or the Greater Antilles (Cody, 1993; Murphy et al., 2000; Queffelec et al., 2018, 2020). Previous studies of hard rocks such as jadeitite, used for the manufacture of a polished ax, have already highlighted such trade networks from the Greater Antilles to the Lesser Antilles (e.g., Harlow et al., 2006; Garcia-Casco et al., 2013; Schertl et al., 2019). The greenish translucent material sudoite could therefore have been part of the batch of exotic colored rocks brought to the Lesser Antilles as part of the pan-Caribbean trade network described for this period (e.g., Rodriguez, 1993; Hofman et al., 2007; Rodriguez Ramos, 2010; Laffoon et al., 2014). It should also be noted that a source of nephrite, a material frequently found in collections of ornamental objects from the same period, was recently discovered on the northern coast of Colombia (Acevedo Gómez et al., 2018), not that far from the Panamanian or Costa Rican ophiolites.

Of the nine artifacts identified as sudoite, eight are of centimeter-sized dimension, consistent with most of the other lithic beads and pendants of Amerindian cultures (e.g., Murphy et al., 2000; Queffelec et al., 2018, 2020; Falci et al., 2020). Such small pieces require only limited sizes of mineralization. Only one pendant (GD-02-003) has a size of several centimeters. Even though such large volumes of raw material may be rare, they must have been available at the outcrop itself to be exploited by the Amerindians, since it is unlikely that this kind of sheet silicate does occur in secondary deposits given its fragility. These outcrops must be of very limited dimensions, which may explain the absence of known localities so far.

All of these objects were found on three islands of the French Lesser Antilles distributed along the

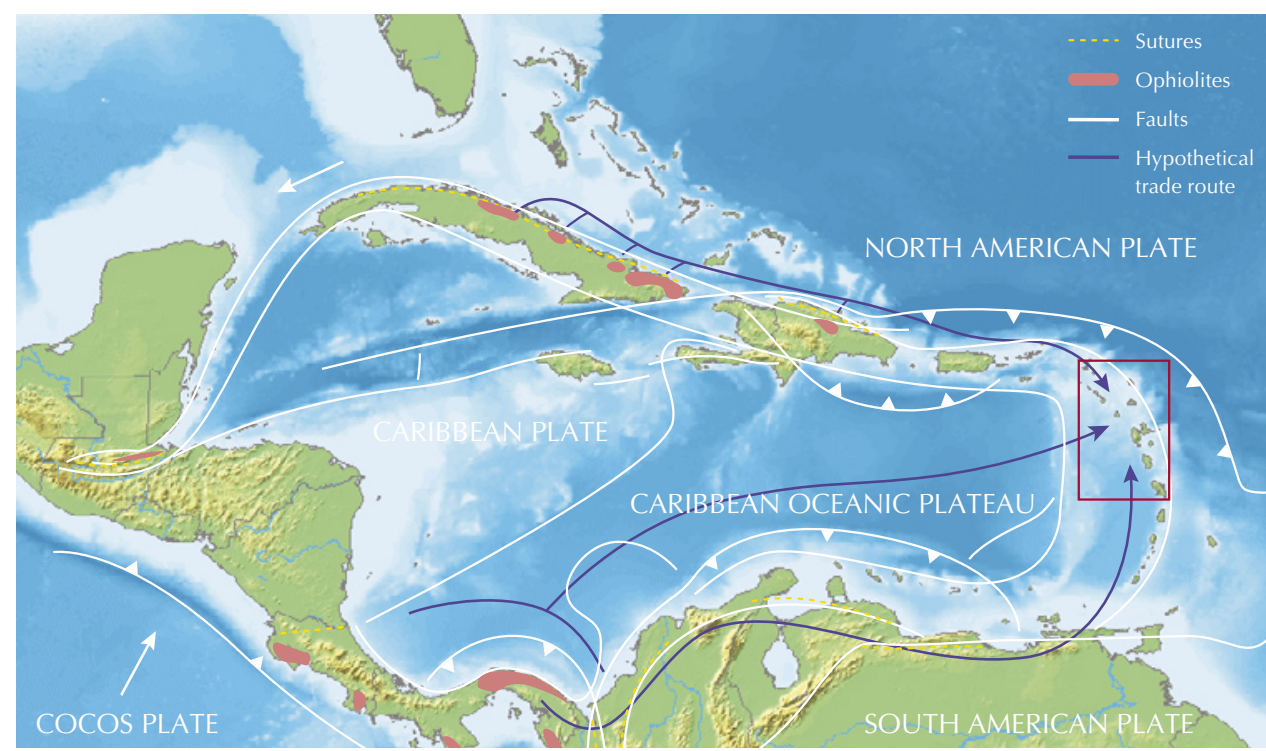

Figure 17. Plate tectonic configuration and major structural features in the Caribbean region, with the presence of ophiolites reported (after figure 1 in Garcia-Gasco et al., 2006). The red rectangle on the right represents the area where the nine artifacts were recovered from archaeological excavations. Modified after GarciaGasco et al. (2011). 
Caribbean arc. Sudoite has been identified in every archaeological site that delivered dozens of lapidary artifacts known for these three islands. This underscores the possibility that this newly identified lapidary material could also be found among the archaeological collections of other islands distributed in the same cultural network, if detailed analytical studies were carried out. Identifying this material in archaeological collections will require analytical techniques such as Raman spectroscopy, which is not systematically used by archaeologists, especially in the Caribbean.

\section{CONCLUSIONS}

Sudoite was unambiguously identified using a multianalytical strategy combining methods both structural (Raman and infrared spectroscopy, X-ray diffraction, SEM) and chemical (XRF and EDS). This magnesium-rich di-trioctahedral sheet silicate from the chlorite group is confirmed to be the raw material used by the Amerindians of the Early Ceramic period in the Lesser Antilles to create the nine personal ornaments in this study. It is also the first time this material has been identified as being used for lapidary craft from any period, and the first time it has been described in sizes suitable for carving. The origin of the color and the long-wave UV luminescence properties have also been explored by means of UV-Vis-
NIR spectroscopy and spectrofluorimetry. The greenish color is related to the presence of iron (both $\mathrm{Fe}^{2+}$ and $\left.\mathrm{Fe}^{3+}\right)$, with a possible contribution from $\mathrm{V}^{3+}$ that would narrow the transmission window for some artifacts. The cause of the UV luminescence remains unclear.

Such a rare material is of interest for the archaeologist, since it may offer valuable information on trade networks during the period under consideration. Sudoite is one of the green rocks used in Amerindian lapidary craftsmanship in the Lesser Antilles, possibly originating from the Greater Antilles, or Central or South America. Based on metamorphic geology, it is possible to consider the origin of sudoite in the ophiolitic formations located at the sutures of the collisions between the Caribbean plate and the North American and Cocos plates. These particular zones are therefore found mainly in northern Cuba, Panama, and Costa Rica, but finding outcrops of this material will prove very difficult due to their limited size in primary deposits and their limited dispersal in secondary deposits. As it would be particularly important to specify the archaeological distribution of the sudoite raw material and its geographical origin, this calls for further detailed analytical studies of objects from the archaeological sites, both in the Antilles and on the nearby continent, and for detailed field prospecting in the areas that might have generated this material.

\section{ABOUT THE AUTHORS}

Mr. Queffelec is a PhD student and CNRS engineer in archaeometry at the UMR5199 PACEA (CNRS, University of Bordeaux, Ministère de la Culture). Mr. Bellot-Gurlet is a full professor of analytical chemistry at the UMR8233 MONARIS (Sorbonne University, CNRS). Mr. Foy is a CNRS engineer in archaeometry at the UMR3685 NIMBE (CNRS, CEA, University of Paris-Saclay). Mr. Lefrais is a CNRS engineer in archaeometry at the UMR5060 CRP2A (CNRS, Bordeaux Montaigne University). Mr. Fritsch is full professor in physics and gemologist at the UMR6502 IMN (University of Nantes, CNRS).

\section{ACKNOWLEDGMENTS}

This study was conducted through the Programme Collectif de Recherche "Parures amérindiennes en matériaux lithiques dans les Antilles Françaises: minéralogie, sources géologiques et fabrication," funded by the Guadeloupe Regional Service of Archaeology, the Guadeloupe Regional Council, and the Martinique Regional Service of Archaeology. This research was also partially supported by the LabEx LaScArBx research program (ANR-10$\angle A B X-52)$. We thank the Musée Départemental Edgar Clerc, the Musée Départemental d'Archéologie et de Préhistoire de la Martinique, and François Petit for granting access to the material. We are grateful to Blanca Moquet for refractive index spot readings. We thank the three anonymous reviewers for their thorough evaluation that helped improved the quality of this article. This study received financial support from the French government in the framework of the University of Bordeaux's IdEx "Investments for the Future" program/GPR "Human Past."

\section{REFERENCES}

Acevedo Gómez N., Scharff M.W., Garcia-Casco A., Sáenz-Samper J. (2018) Placas aladas de las sociedades Nahuange y Tairona (100-1600 DC), Sierra Nevada de Santa Marta, Colombia: materia prima y areas de procedencia. Latin American Antiquity, Vol.
29, No. 4, pp. 774-792, http://dx.doi.org/10.1017/laq.2018.51 Albee A.L. (1962) Relationships between the mineral association, chemical composition and physical properties of the chlorite series. American Mineralogist, Vol. 47, No. 7-8, pp. 851-870, 
http://dx.doi.org/10.1346/CCMN.1989.0370301

Arem J.E. (1987) Color Encyclopedia of Gemstones, 2nd ed. Van Nostrand Reinhold, New York, 248 pp.

Bailey S.W. (1980) Summary of recommendations of AIPEA nomenclature committee on clay minerals. American Mineralogist, Vol. 65, No. 1-2, pp. 1-7.

Bailey S.W., Lister J.S. (1989) Structures, compositions, and X-ray diffraction identification of dioctahedral chlorites. Clays and Clay Minerals, Vol. 37, No. 3, pp. 193-202, http://dx.doi.org/10.1346/CCMN.1989.0370301

Beaufort D., Rigault C., Billon S., Billault V., Inoue A., Inoue S., Patrier P. (2015) Chlorite and chloritization processes through mixed-layer mineral series in low-temperature geological systems-a review. Clay Minerals, Vol. 50, No. 4, pp. 497-523, http://dx.doi.org/10.1180/claymin.2015.050.4.06

Bérard B. (2013) The Saladoid. In W. Keegan, C. Hofman, and R. Rodriguez Ramos, Eds., The Oxford Handbook of Caribbean Archaeology. Oxford University Press, pp. 184-197.

- (2019) About boxes and labels: A periodization of the Amerindian occupation of the West Indies. Journal of Caribbean Archaeology, Vol. 19, pp. 17.

Billault V., Beaufort D., Patrier P., Petit S. (2002) Crystal chemistry of Fe-sudoites from uranium deposits in the Athabasca Basin (Saskatchewan, Canada). Clays and Clay Minerals, Vol. 50, No. 1, pp. 70-81, http://dx.doi.org/10.1346/000986002761002847

Bishop J.L., Lane M.D., Dyar M.D., Brown A.J. (2008) Reflectance and emission spectroscopy study of four groups of phyllosilicates: smectites, kaolinite-serpentines, chlorites and micas. Clay Minerals, Vol. 43, No. 1, pp. 35-54, http://dx.doi.org/10.1180/claymin.2008.043.1.03

Bonnissent D. (2008) Archéologie précolombienne de l'île de SaintMartin, Petites Antilles (3300 BC-1600 AD). PhD thesis, Université Aix-Marseille, 261 pp.

Brigatti M.F., Malferrari D., Laurora A., Elmi C., Mottana A. (2011) Structure and mineralogy of layer silicates: Recent perspectives and new trends. In M.F. Brigatti, and A. Mottana, Eds., Layered Mineral Structures and Their Application in Advanced Technologies. European Mineralogical Union Notes in Mineralogy Series, Vol. 11, pp. 1-71. Mineralogical Society of Great Britain and Ireland, London.

Bukanov V.V. (2006) Russian Gemstones. Granit, Prague, 472 pp.

Clark R.N. (1999) Spectroscopy of rocks and minerals, and principles of spectroscopy. In A.N. Rencz, Ed., Manual of Remote Sensing for the Earth Sciences, 3rd ed., John Wiley \& Sons, Inc., New York, pp. 3-58.

Clark R.N., King T.V., Klejwa M., Swayze G.A., Vergo N. (1990) High spectral resolution reflectance spectroscopy of minerals. Journal of Geophysical Research: Solid Earth, Vol. 95, No. B8, pp. 12653-12680, http://dx.doi.org/10.1029/JB095iB08p12653

Cody A.K. (1993) Distribution of exotic stone artifacts through the Lesser Antilles: Their implications for prehistoric interaction and exchange. In A. Cummins and P. King, Eds., Proceedings of the 14th International Congress for Caribbean Archaeology, Barbados, pp. 204-226.

Czaja M., Kadziołka-Gaweł M., Lisiecki R., Bodył-Gajowska S., Mazurak Z. (2014) Luminescence and other spectroscopic properties of purple and green Cr-clinochlore. Physics and Chemistry of Minerals, Vol. 41, No. 2, pp. 115-126, http://dx.doi.org/10.1007/s00269-013-0629-x

Daniels E.J., Altaner S.P., Marshak S., Eggleston J.R. (1990) Hydrothermal alteration in anthracite from eastern Pennsylvania: Implications for mechanisms of anthracite formation. Geology, Vol. 18, No. 3, pp. 247-250, http://dx.doi.org/10.1130/00917613(1990)018\%3C0247:HAIAFE\%3E2.3.CO;2

Desautels P.E. (1973) L'univers des pierres précieuses. Arthaud, Paris, $252 \mathrm{pp}$.

Drouin D., Couture A.R., Joly D., Tastet X., Aimez V., Gauvin R. (2007) CASINO V2.42-A fast and easy-to-use modeling tool for scanning electron microscopy and microanalysis users. Scanning, Vol. 29, No. 3, pp. 92-101, http://dx.doi.org/https://doi.org/10.1002/sca.20000

Duda R., Relj L. (1999) Les pierres précieuses. Gründ, Paris, 407 pp.

v. Engelhardt W., Müller G., Kromer H. (1962) Dioktaedrischer Chlorit ("Sudoit") in Sedimenten des Mittleren Keupers von Plochingen (Württ.). Naturwissenschaften, Vol. 49, No. 9, pp. 205-206, http://dx.doi.org/10.1007/BF00633957

Falci C.G., Knaf A.C.S., van Gijn A., Davies G.R., Hofman C.L. (2020) Lapidary production in the eastern Caribbean: A typotechnological and microwear study of ornaments from the site of Pearls, Grenada. Archaeological and Anthropological Sciences, Vol. 12, No. 2, Article no. 53, 16 pp. http://dx.doi.org/10.1007/s12520-019-01001-4

Farmer V.C. (1974) The layer silicates. In V.C. Farmer, Ed., The Infrared Spectra of Minerals, Mineralogical Society, London, pp. 331-363.

Fransolet A.-M., Bourguignon P. (1978) Di/trioctahedral chlorite in quartz veins from the Ardenne, Belgium. The Canadian Mineralogist, Vol. 16, No. 3, pp. 365-373.

Fritsch E., Waychunas G.A. (1994) Gemstones. In M. Robbins, Ed., Fluorescence: Gems and Minerals Under Ultraviolet Light. Geoscience Press, Phoenix, Arizona, pp. 149-174.

Gaft M., Reisfeld R., Panczer G. (2005) Luminescence Spectroscopy of Minerals and Materials. Springer-Verlag, Berlin and Heidelberg, 356 pp., http://dx.doi.org/10.1007/b137490

Gaines R.V., Dana J.D., Dana E.S. (1997) Dana's New Mineralogy: The System of Mineralogy of James Dwight Dana and Edward Salisbury Dana. John Wiley, New York.

Garcia-Casco A., Torres-Roldán R.L., Iturralde-Vinent M.A., Millán G., Cambra K.N., Lázaro C., Vega A.R. (2006) High pressure metamorphism of ophiolites in Cuba. Geologica Acta, Vol. 4, No. 1, pp. 63-88, http://dx.doi.org/10.1344/105.000000358

Garcia-Casco A., Proenza J.A., Iturralde-Vinent M.A. (2011) Subduction zones of the Caribbean: The sedimentary, magmatic, metamorphic and ore-deposit records. Geologica Acta, Vol. 9 No. 3-4, pp. 217-224, http://dx.doi.org/10.1344/105.000001745

Garcia-Casco A., Knippenberg S., Ramos R.R., Harlow G.E., Hofman C., Pomo J.C., Blanco-Quintero I.F. (2013) Pre-Columbian jadeitite artifacts from the Golden Rock Site, St. Eustatius, Lesser Antilles, with special reference to jadeitite artifacts from Elliot's, Antigua: Implications for potential source regions and long-distance exchange networks in the Greater Caribbean. Journal of Archaeological Science, Vol. 40, No. 8, pp. 31533169, http://dx.doi.org/10.1016/j.jas.2013.03.025

Gates-Rector S., Blanton T. (2019) The Powder Diffraction File: A quality materials characterization database. Powder Diffraction, Vol. 34, No. 4, pp. 352-360, http://dx.doi.org/10.1017/S0885715619000812

Goffé B., Michard A., Kienast J.R., Le Mer O. (1988) A case of obduction-related high-pressure, low-temperature metamorphism in upper crustal nappes, Arabian continental margin, Oman: P$\mathrm{T}$ paths and kinematic interpretation. Tectonophysics, Vol. 151, No. 1, The Ophiolites of Man, pp. 363-386, http://dx.doi.org/10.1016/0040-1951/88/90253-3

Hammersley A.P. (2016) FIT2D: A multi-purpose data reduction, analysis and visualization program. Journal of $A p$ plied Crystallography, Vol. 49, No. 2, pp. 646-652, http://dx.doi.org/10.1107/S1600576716000455

Harlow G.E., Murphy A.R., Hozjan D.J., de Mille C.N., Levinson A.A. (2006) Pre-Columbian jadeite axes from Antigua, West Indies: Description and possible sources. The Canadian Mineralogist, Vol. 44, No. 2, pp. 305-321, http://dx.doi.org/10.2113/gscanmin.44.2.305

Hofman C.L., Bright A.J., Boomert A., Knippenberg S. (2007) Island rhythms: The web of social relationships and interaction networks in the Lesser Antillean Archipelago between 400 B.C. and A.D. 1492. Latin American Antiquity, Vol. 18, No. 3, pp 243-268, http://dx.doi.org/10.2307/25478180 
Hunt G.R. (1977) Spectral signatures of particulate minerals in the visible and near infrared. Geophysics, Vol. 42, No. 3, pp. 501513, http://dx.doi.org/10.1190/1.1440721

Jige M., Kitagawa R., Zaykov V.V., Sinyakovskaya I. (2003) Surface microtopography of sudoite. Clay Minerals, Vol. 38, No. 3, pp. 375-382, http://dx.doi.org/10.1180/0009855033830104

Johnston W.D. (1965) Optical spectra of the various valence states of vanadium in $\mathrm{Na}_{2} \mathrm{O} \cdot 2 \mathrm{SiO}_{2}$ glass. Journal of the American Ceramic Society, Vol. 48, No. 12, pp. 608-611, http://dx.doi.org/10.1111/j.1151-2916.1965.tb14688.x

Kohyama N. (2000) In memory of Prof. Toshio Sudo. Clay Science, Vol. 11, No. 2, pp. 103-105, http://dx.doi.org/10.11362/jcssjclayscience1960.11.103

Krebs J.J., Maisch W.G. (1971) Exchange effects in the optical-absorption spectrum of $\mathrm{Fe}^{3+}$ in $\mathrm{Al}_{2} \mathrm{O}_{3}$. Physical Review $B$, Vol. 4 , No. 3, pp. 757-769, http://dx.doi.org/10.1103/PhysRevB.4.757

Laffoon J.E., Ramos R.R., Baik L.C., Storde Y.N., Lopez M.R., Davies G.R., Hofman C.L. (2014) Long-distance exchange in the precolonial Circum-Caribbean: A multi-isotope study of animal tooth pendants from Puerto Rico. Journal of Anthropological Archaeology, Vol. 35, pp. 220-233, http://dx.doi.org/10.1016/j.jaa.2014.06.004

Lafuente B., Downs R.T., Yang H., Stone N. (2016) The power of databases: The RRUFF project. In T. Armbruster and R.M. Danisi, Eds., Highlights in Mineralogical Crystallography, pp. 1-30. W. De Gruyter, Berlin, http://dx.doi.org/10.1515/9783110417104003

Lauf R.J. (2010) Collector's guide to the chlorite group. Rocks $\uplus$ Minerals, Vol. 85, No. 4, pp. 318-325, http://dx.doi.org/10.1080/00357521003727272

Lewis J.F., Draper G., Proenza Fernández J.A., Espaillat J., Jiménez J. (2006) Ophiolite-related ultramafic rocks (serpentinites) in the Caribbean region: A review of their occurrence, composition, origin, emplacements and Ni-Laterite soil formation. Geologica Acta, Vol. 4, No. 1-2, pp. 237-263, http://dx.doi.org/10.1344/105.000000368

Madejová J., Gates W.P., Petit S. (2017) IR spectra of clay minerals. Developments in Clay Science, Vol. 8, pp. 107-149, http://dx.doi.org/10.1016/B978-0-08-100355-8.00005-9

Manutchehr-Danai M. (2005) Dictionary of Gems and Gemology, 2nd ed. Springer, Berlin, 879 pp.

Mattson S.M., Rossman G.R. (1987) Identifying characteristics of charge transfer transitions in minerals. Physics and Chemistry of Minerals, Vol. 14, No. 1, pp. 94-99, http://dx.doi.org/10.1007/BF00311152

von Müller G. (1961) Vorläufige Mitteilung über ein neues dioktaedrisches Phyllosilikat der Chlorit-Gruppe. Neues Jahrbuch für Mineralogie, Monatshefte, Vol. 1961, pp. 112-120.

Murphy A.R., Hozjan D.J., de Mille C.N., Levinson A.A. (2000) Pre-Columbian gems and ornamental materials from Antigua, West Indies. Ge G, Vol. 36, No. 2, pp. 234-245, http://dx.doi.org/10.5741/GEMS.36.3.234

Nägele K., Posth C., Orbegozo M.I., Armas Y.C. de, Godoy S.T.H., Herrera U.M.G., Nieves-Colón M.A., Sandoval-Velasco M., Mylopotamitaki D., Radzeviciute R., Laffoon J., Pestle W.J., Ramos-Madrigal J., Lamnidis T.C., Schaffer W.C., Carr R.S., Day J.S., Antúnez C.A., Rivero A.R., Martínez-Fuentes A.J., Crespo-Torres E., Roksandic I., Stone A.C., Lalueza-Fox C., Hoogland M., Roksandic M., Hofman C.L., Krause J., Schroeder H. (2020) Genomic insights into the early peopling of the Caribbean. Science, http://dx.doi.org/10.1126/science.aba8697

O'Donoghue M. (2006) Gems, 6th ed. Elsevier, Oxford, UK, 904 pp.
Palanza V., Galli A., Lorenzi R., Moretti F., Mozzati M.C., Paleari A., Spinolo G. (2010) Luminescence study of transition metal ions in natural magmatic and metamorphic yellow sapphires. In IOP Conference Series: Materials Science and Engineering, 15. IOP Publishing, http://dx.doi.org/10.1088/1757$899 X / 15 / 1 / 012086$

Queffelec A., Fouéré P., Paris C., Stouvenot C., Bellot-Gurlet L. (2018) Local production and long-distance procurement of beads and pendants with high mineralogical diversity in an early Saladoid settlement of Guadeloupe (French West Indies). Journal of Archaeological Science: Reports, Vol. 21, pp. 275288, http://dx.doi.org/10.1016/j.jasrep.2018.07.011

Queffelec A., Fouéré P., Bellot-Gurlet L., Bérard B. (2020) Stone ornaments from Guadeloupe and Martinique Early Ceramic period sites (200 $\mathrm{BC}-\mathrm{AD} 400$ ), detailed analysis and comparison with a Late Ceramic period site (AD 750 - 1000). Journal of Caribbean Archaeology, Vol. 20, pp. 1-44.

Queffelec A., Fouéré P., Caverne J.-B. (2021) A database of lapidary artifacts in the Caribbean for the Ceramic Age. Journal of Open Archaeology Data, Vol. 9, pp. 11, http://dx.doi.org/10.5334/joad.74

Reynard B., Bezacier L., Caracas R. (2015) Serpentines, talc, chlorites, and their high-pressure phase transitions: A Raman spectroscopic study. Physics and Chemistry of Minerals, Vol. 42, No 8, pp. 641-649, http://dx.doi.org/10.1007/s00269-015-0750-0

Rodriguez M. (1993) Early trade networks in the Caribbean. In A. Cummins and P. King, Eds., Proceedings of the 14th International Congress for Caribbean Archaeology. International Association for Caribbean Archaeology, Barbados, pp. 306-314.

Rodriguez Ramos R. (2010) What is the Caribbean? An archaeological perspective. Journal of Caribbean Archaeology, Vol. 3, pp. 19-51.

Rouse I. (1992) The Tainos: Rise and Decline of the People Who Greeted Columbus. Yale University Press, New Haven, Connecticut.

Ruiz Cruz M.D., de Galdeano C.S. (2005) Compositional and structural variation of sudoite from the Betic Cordillera (Spain): A TEM/AEM study. Clays and Clay Minerals, Vol. 53, No. 6, pp. 639-652, http://dx.doi.org/10.1346/CCMN.2005.0530610

Schertl H.-P., Maresch W.V., Knippenberg S., Hertwig A., Belando A.L., Ramos R.R., Speich L., Hofman C.L. (2019) Petrography, mineralogy and geochemistry of jadeite-rich artefacts from the Playa Grande excavation site, northern Hispaniola: Evaluation of local provenance from the Río San Juan Complex. Geological Society, London, Special Publications, Vol. 474, No. 1, pp. 231253, http://dx.doi.org/10.1144/SP474.3

Schreyer W. (1988) Experimental studies on metamorphism of crustal rocks under mantle pressures. Mineralogical Magazine, Vol. 52, No. 364, pp. 1-26, http://dx.doi.org/10.1180/minmag.1988.052.364.01

Shirozu H., Ishida K. (1982) Infrared study of some $7 \backslash A A$ and 14 AA layer silicates by deuteration. Mineralogical Journal, Vol. 11, No. 4, pp. 161-171, http://dx.doi.org/10.2465/minerj.11.161

Spinolo G., Fontana I., Galli A. (2007) Optical absorption spectra of $\mathrm{Fe}^{2+}$ and $\mathrm{Fe}^{3+}$ in beryl crystals. Physica status solidi (b), Vol. 244, No. 12, pp. 4660-4668, http://dx.doi.org/10.1002/pssb.200790018

Theye T., Seidel E., Vidal O. (1992) Carpholite, sudoite, and chloritoid in low-grade high-pressure metapelites from Crete and the Peloponnese, Greece. European Journal of Mineralogy, Vol. 4, No. 3, pp. 487-508, http://dx.doi.org/10.1127/ejm/4/3/0487

Wang A., Freeman J.J., Jolliff B.L. (2015) Understanding the Raman spectral features of phyllosilicates. Journal of Raman Spectroscopy, Vol. 46, No. 10, pp. 829-845, http://dx.doi.org/10.1002/jrs.4680

Wilson S.M. (2007) Archaeology of the Caribbean. Cambridge University Press, New York, 205 pp. 